\title{
Study on Dynamic Mechanical Properties and Failure Mechanism of Sandstones under Real-Time High Temperature
}

\author{
JiaZhi Zhang, ${ }^{1}$ Ming Li $\mathbb{D}^{2},{ }^{2}$ Gang Lin, ${ }^{1}$ Lianying Zhang $\mathbb{D}^{3}$ Hao Yu, ${ }^{1}$ and Kui $\mathrm{Di}^{2}$ \\ ${ }^{1}$ School of Mechanics and Civil Engineering, China University of Mining and Technology, Xuzhou, Jiangsu 221116, China \\ ${ }^{2}$ State Key Laboratory for Geomechanics and Deep Underground Engineering, China University of Mining and Technology, Xuzhou, \\ Jiangsu 221116, China \\ ${ }^{3}$ School of Civil Engineering, Xuzhou University of Technology, Xuzhou, 221018 Jiangsu, China
}

Correspondence should be addressed to Ming Li; mingl@cumt.edu.cn

Received 2 October 2021; Revised 17 October 2021; Accepted 27 October 2021; Published 8 December 2021

Academic Editor: Fazhi Yan

Copyright (c) 2021 JiaZhi Zhang et al. This is an open access article distributed under the Creative Commons Attribution License, which permits unrestricted use, distribution, and reproduction in any medium, provided the original work is properly cited.

\begin{abstract}
The research on dynamic mechanical properties of rocks under high temperature is the basis for safe and efficient implementation of deep coal mining and underground coal gasification engineering. In this paper, the split Hopkinson bar (SHPB) with real-time high-temperature function was adopted to systematically study dynamic mechanical properties of sandstones. The research showed that under the condition of a fixed temperature, with the increase of strain rate, the dynamic compressive strength and dynamic peak strain of sandstone increased gradually, and the variation of dynamic elastic modulus with strain rate was not obvious. With the increase of temperature, the dynamic compressive strength of sandstone increased first and then decreased, the dynamic peak strain increased gradually, and the dynamic elastic modulus decreased overall. The variation law of macroscopic failure mode and energy dissipation density with temperature was revealed, and the change mechanism was explained considering the influence of high temperature on the internal structure of sandstone. Based on the principle of component combination and the theory of micro-element strength distribution, the dynamic statistical damage constitutive model was established, and its parameters had certain physical significance. Compared with the experimental results, the established model can well describe the dynamic stress-strain relationship of sandstone under real-time high temperature.
\end{abstract}

\section{Introduction}

Rock dynamic mechanic problems subjected to hightemperature environment are widespread in mine geotechnical engineering. In coal underground gasification engineering, the local temperature in the combustion area of the coal underground gasifier exceeds $1000^{\circ} \mathrm{C}$ [1], and there will be significant impact loads generated by the roof collapse. Thus, the stability of the surrounding rock of the gasifier has remarkable potential hazards under the coupled effects of high temperature and dynamic load. Furthermore, nuclear waste repositories [2] and deep coal mining [3, 4] are all facing the above environmental issues. Therefore, investigating the dynamic mechanical properties of rocks subjected to high-temperature environment is of great significance to developing the above mine geotechnical engineering.
The dynamic mechanical properties of rocks under hightemperature circumstances have caused scholars' widespread concern. Nevertheless, due to the limitation of test conditions, the majority of scholars adopted the test method that the sample was heated before the implementation of the SHPB test, in the early research $[5,6]$. Macroscopically, when the temperature was fixed, the dynamic peak strain and strength of rock increased with the increase of the strain rate, which was basically similar to dynamic response characteristics of rocks at room temperature [7]. In contrast, under the condition of fixed strain rate, with the increase of temperature, the dynamic compressive strength of rock approximately firstly increased and then decreased. It is notable that there are differences in inflection temperature of mechanical characteristics of varied rock types [8]. The change of macroscopically mechanical characteristics is closely related to the variation of physical properties of 
rocks. Research shows that temperature plays a significant role in physical properties of rocks, such as reducing density $[9,10]$, increasing porosity [11-13], and reducing longitudinal wave velocity $[14,15]$, which is an essential reason for the variation of mechanical characteristics $[6,16]$. In addition, the material composition and microstructure characteristics of rocks after thermal treatment were systematically studied by microstructure observation methods, such as X-ray diffraction [17] and SEM scanning $[18,19]$. The change mechanism of dynamic mechanical properties of rocks after thermal treatment was clarified [20]. With the deepening of investigation, scholars found that the research findings of rock dynamic mechanical properties after thermal treatment could not fully account for the engineering issues such as the stability of rock mass structure under high-temperature environment. It is necessary to experiment with rock materials under real-time high temperature and impact loading. In the early-stage research on the dynamic mechanical properties of rock under real-time high temperature, the sample was heated to the specified temperature in the heating furnace and then was quickly transferred to the SHPB system for dynamic test. By using this method, Chen et al. adopted a specially manufactured microwave-heating automatic time-controlled SHPB apparatus to systematically study dynamic properties of normal concrete at elevated temperature from $20^{\circ} \mathrm{C}$ up to $950^{\circ} \mathrm{C}$. The test results showed that the dynamic strength and stress-strain curve of normal concrete at high temperatures still experienced remarkable strain rate effects. Meanwhile, the failure appearances of normal concrete subjected to both high temperature and high strain rate loading were significantly different from those of concrete at ambient temperature [21]. Liu and Xu carried out a dynamic compress experiment with an improved SHPB test system with a tube-type heating furnace, and there was a temperature compensation for about 2 minutes to make up for the heat loss. The test results demonstrated that the temperatures at which the strain rates affect dynamic compressive strength and peak strain most were $800^{\circ} \mathrm{C}$ and $1000^{\circ} \mathrm{C}$, respectively. The temperatures at which the strain rates affect dynamic compressive strength and peak strain weakest were $1000^{\circ} \mathrm{C}$ and room temperature, respectively [22]. Huang et al. heated the sample to the temperature value, which considered the heat loss during the high-temperature transfer process. The dynamic test results pointed out that there was a strain rate threshold for concrete. If the strain rate was less than the threshold, there was a temperature softening effect. Conversely, if the strain rate was greater than the threshold, there was a temperature hardening effect [23]. However, the heating-transferring method has hidden dangers to the safety of researchers, and the temperature variation caused by the heat loss during the transfer of samples cannot be controlled.

The essence of rock failure is the macroscopic performance of energy absorption and release during the loading process [24]. Therefore, it is significant to reveal the dynamic failure characteristics of high-temperature rocks based on energy dissipation characteristics. He et al. conducted uniaxial compression tests for fifteen different rocks, and the evo- lution characteristics of dissipated energy for the fifteen rocks were studied. Moreover, the dissipation energy coefficients were introduced to study evolution characteristics and determine the strength of rocks. The results showed that the evolution of dissipation energy coefficients exhibited significant deformation properties of rocks. They linearly increased with the compaction strength and decreased with the yield strength and peak strength [25]. Zhang et al. systematically investigated thermal damage and energy evolution characteristics in process of impact failure of sandstone after high-temperature treatment and pointed out that the thresholds of damage strain energy release rate of sandstone sample are $200^{\circ} \mathrm{C}$ and $800^{\circ} \mathrm{C}$ [26]. Yin et al. [27] carried out a uniaxial dynamic compression test of coal rock under high temperature, the relationship between energy and time under different temperature conditions was obtained, and the variation law of energy and failure mode of coal and rock with temperature in the process of deformation and failure was summarized. Li et al. studied the influence of heating rate on the dynamic mechanical performance of coal measure rocks after heat treatment and pointed out that the energy dissipation during fracturing was correlated closely to fracture characteristics [28]. Wang et al. conducted the static and dynamic compression tests on granite after heat treatment and defined the rate of energy dissipation change, which could be used to identify the deformation stages of rocks and determine positions of failure points in the stress-strain curve [29]. Shu et al. studied the thermal effect on the energy dissipation of rocks during the dynamic cyclic loading and analyzed correlations among the energy dissipation, energy dissipation rate, impact times, accumulated absorbed energy per volume, failure mode, and temperature [30].

In addition to the study of energy dissipation characteristics, the establishment of constitutive models to reflect dynamic mechanical properties of rocks is one of the current research focuses. Some scholars adopted the damage statistical mathematical theory to establish a mechanical model with a certain degree of generality, which could better describe dynamic damage characteristics and stress-strain relationship of rocks under different conditions. Ma et al. established a dynamic model of frozen constitutive sandy clay, which described dynamic mechanical behaviors of frozen sandy clay under the condition of confining pressure, strain rate, and freezing temperature [31]. Wang et al. proposed a statistical damage constitutive model of granite under high temperature and discussed factors affecting values of model fitting parameters [32]. Wang et al. defined damage variables of the rock by continuous factors, strain equivalence principle, and statistical damage theory. They also established a damage constitutive model of rock under frequent disturbances in the process of unloading high static stress [33]. Liu et al. proposed an experimental method to obtain the stress and strain of coal in coal-rock combined samples and established two damage constitutive models of coal, which could accurately describe stress-strain curves of coal in coal-rock samples and reflect the influences of rock, coal-rock combination form, and coal-rock height ratio [34]. In addition, some scholars [35] classified the coupling 
damage as meso-damage induced by wet-dry cycles and macrodamage induced by impact load, and the loading rate effect was considered as the load damage. Besides, they concluded a constitutive model of coupling damage based on Lemaitre's strain equivalent assumption.

At present, most of research results focus on dynamic mechanical properties and damage mechanism of rocks after high temperature. There are few studies on dynamic mechanical properties and constitutive models of rocks under real-time high temperature. In this paper, the split Hopkinson pressure bar test system with real-time hightemperature function (HT-SHPB) will be adopted to conduct impact loading tests on sandstones at different temperatures $\left(25^{\circ} \mathrm{C}-800^{\circ} \mathrm{C}\right)$. The response characteristics of sandstone mechanical properties will be studied under high temperature and high strain rate loading. By analyzing the energy dissipation law in the failure process of sandstone, the failure mechanism of sandstones will be revealed under high temperature and high strain rate. Furthermore, a dynamic constitutive model of high-temperature rock will be constructed based on statistical damage theory. The research results are aimed at promoting the development of mine geotechnical engineering under high-temperature environment.

\section{Experimental Setup and Methods}

2.1. Sample Preparation. The samples were fabricated into cylinders with a diameter of $50 \mathrm{~mm}$ and height of $50 \mathrm{~mm}$. Meanwhile, according to the standard suggested by the International Society for Rock Mechanics (ISRM) [36], the samples were ground to ensure the parallelism $(\leq 0.02 \mathrm{~mm})$ and the flatness $(\leq 0.05 \mathrm{~mm})$. Physical and mechanical tests were carried out on standard samples (cylinder with a diameter of $50 \mathrm{~mm}$ and height of $100 \mathrm{~mm}$ ) at room temperature $\left(25^{\circ} \mathrm{C}\right)$. The basic physical and mechanical parameters of the standard samples are shown in Table 1.

2.2. Experiment Equipment. The dynamic compress loading test was carried out on real-time high temperature split Hopkinson test system (HT-SHPB), which mainly consists of a temperature control system, bar system, launching system, and data acquisition and analysis system, as shown in Figure 1. The bar system mainly consists of a striker, an incident bar, a transmitted bar, and an energy absorption device. The bars comprise of high-strength low-carbon steel, the elastic modulus is $210 \mathrm{GPa}$, and the longitudinal wave velocity is $5450 \mathrm{~m} / \mathrm{s}$. Moreover, the shape of the striker is the cylinder, the length is $500 \mathrm{~mm}$, and the striker is driven by pressurized nitrogen.

The launching control system mainly composed of a gas cylinder and console. The data acquisition and analysis system mainly comprise a velocity test device and ultradynamic strain test device.

The heating device in the temperature control system is a tube-type heating furnace, which is made up of corundum tubes and heat-resistant steel. The heating furnace's heat preservation layer comprises an aluminum silicate fiber blanket with excellent thermal insulation property. In addition, the temperature measuring element of the heating furnace is a K-type thermocouple, and its heating element is a
TABLE 1: Basic physical and mechanical properties of sandstone samples.

\begin{tabular}{lccccc}
\hline$\sigma_{c}(\mathrm{MPa})$ & $\varepsilon_{c}(\%)$ & $E_{c}(\mathrm{GPa})$ & $v\left(\mathrm{~km} \cdot \mathrm{s}^{-1}\right)$ & $\rho\left(\mathrm{kg} \cdot \mathrm{m}^{-3}\right)$ & $\mu$ \\
\hline 58.99 & 2.39 & 7.93 & 2.012 & 2141 & 0.174 \\
\hline
\end{tabular}

Where $\sigma_{c}$ denotes compressive strength, $\varepsilon_{c}$ denotes peak strain, $E_{c}$ denotes elastic modulus, $v$ denotes acoustic velocity of samples, $\rho$ denotes the density of samples, and $\mu$ denotes Poisson's ratio.

U-type silicon carbon rod. Besides, the maximum design temperature of the heating furnace is $1000^{\circ} \mathrm{C}$, and the temperature control accuracy is $\pm 1^{\circ} \mathrm{C}$, which the temperature controller adjusts. Moreover, the bars are exposed to hightemperature environment for only a few seconds during the test, even at $800^{\circ} \mathrm{C}$ high-temperature experiment, the temperature in the end of bar is still low, and the influence of temperature on the stress wave propagation in the bar can be ignored [17].

The operating principle of the HT-SHPB system is given. First, the sample is heated to a specified temperature in a tube-type heating furnace, and the temperature is kept constant. Then, the incident and transmitted bar are driven by the mechanical claw connected with the air cylinder under the console control, and the automatic alignment and reset of the incident and transmitted bar is achieved. Finally, the impact experiment is carried out. The strain signals in the incident and transmitted bars are transmitted to the ultradynamic strain test device through the strain gauges. Meanwhile, the impact velocity is obtained by the velocity test device. During the whole test process, the samples are all in the inner of tube-type heating furnace, and the rock impact loading test is realized under real-time hightemperature environment.

2.3. Test Process and Test Waveform. In this test, the mechanical responses of sandstone under different temperatures and impact intensities were realized by changing the heating temperature and impact pressure. Based on the background and the test condition, the test temperature gradients were set as $25^{\circ} \mathrm{C}, 100^{\circ} \mathrm{C}, 200^{\circ} \mathrm{C}, 400^{\circ} \mathrm{C}, 600^{\circ} \mathrm{C}$, and $800^{\circ} \mathrm{C}$. The test impact pressures were set as $0.3 \mathrm{MPa}, 0.4 \mathrm{MPa}, 0.5 \mathrm{MPa}, 0.6 \mathrm{MPa}$, and $0.7 \mathrm{MPa}$, of which $0.3 \mathrm{MPa}$ was the minimum pressure that the sample could be destroyed. At $0.7 \mathrm{MPa}$, the sample would be pulverized after impact.

The whole testing procedure is as follows. First, the striker was reset manually, while the transmitted and incident bars were reset automatically, driven by the console. Subsequently, the sample was placed in the inner of the tube-type heating furnace and the position was adjusted. Then, the heating furnace was closed and the clamp was locked. The sample was heated by $5^{\circ} \mathrm{C} / \mathrm{min}$, and the temperature remained constant $6 \mathrm{~h}$ when achieving a specified temperature to guarantee the uniform heating. Finally, the incident bar and the transmitted bar were driven by the alignment console, the samples were clamped in the heating furnace, and the designed impact test was conducted. After the test, the original waveform is processed by three-wave method.

To ensure the stress equilibrium in the loading process of the SHPB test, a copper slice with a diameter of $5 \mathrm{~mm}$ 


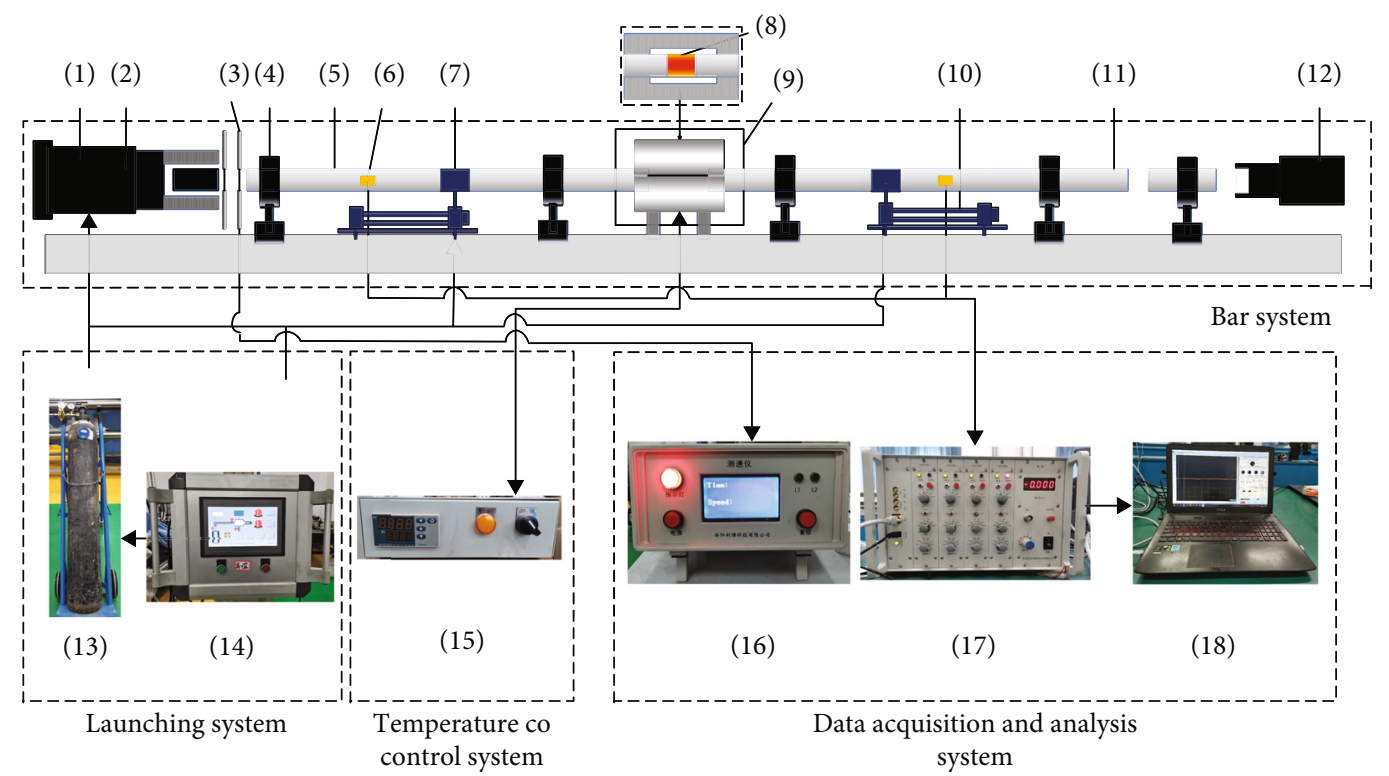

FIGURE 1: Real-time high temperature split Hopkinson test system. (1) Launcher. (2) Striker. (3) Infrared velocity measuring device. (4) Support base. (5) Incident bar. (6) Strain gauges. (7) Mechanical claw. (8) The samples. (9) Tube-type heating furnace. (10) Air cylinder. (11) Transmitted bar. (12) Energy absorption device. (13) Gas cylinder. (14) Console. (15) Temperature controller. (16) Velocity measuring device. (17) Ultradynamic strain test device. (18) Computer.

and a thickness of $1 \mathrm{~mm}$ was attached to the loading end of the incident bar as a pulse shaper. The waveforms are shown in Figure 2. As shown in Figure 2, the incident waves did not demonstrate any prominent lateral vibrations during wave propagation, indicating that the test corresponded to onedimensional wave propagation. The rising edge of the incident wave was slow, the sum of the incident waves and reflected waves were approximately equal to the transmitted wave, and stress equilibrium of the samples was achieved.

\section{Dynamic Response Characteristics of Sandstones under Real-Time High Temperature}

3.1. Stress-Strain Curves. Figure 3 demonstrates stress-strain curves of sandstones under various conditions, of which the stress-strain curves at the same temperature and different strain rates are illustrated in Figure 3(a); the stress-strain curves at the same strain rates and different temperatures are illustrated in Figure 3(b); the typical stress-strain curves are illustrated in Figure 3(c).

As seen in Figures 3(a) and 3(b), at the same temperature, the shapes of stress-strain curves at different strain rates are similar. At the same strain rate, there are obvious differences in the shapes of stress-strain curves at different temperatures. It could be found that the effect of temperature on shapes of stress-strain curves was greater than that of strain rate on the test. In Figure 3(c), the stress-strain curves of sandstone samples under various conditions could be divided into elastic deformation stage, inelastic deformation range, and failure stage. In Figure 3(c), variation laws of stress-strain curve shape with temperature could be obtained at high and low strain rates. As the temperature increased from 25 to $600^{\circ} \mathrm{C}$, the percentage of compaction during the stress-strain curve changed slightly. When the temperature reached $800^{\circ} \mathrm{C}$, the percentage of the elastic stage decreased rapidly, and the plasticity increased, indicating that the elastic deformation behavior of the sandstone sample was most affected by the impact loading at $800^{\circ} \mathrm{C}$.

3.2. Variation Laws of Sandstone Dynamic Compressive Strength with Temperature and Strain Rate. The dynamic peak strength $\sigma_{d}$, dynamic peak strain $\varepsilon_{d}$, and dynamic elastic modulus $E_{d}$ under various conditions were obtained by the stress-strain curves, as shown in Table 2.

Figure 4 reveals change laws of dynamic peak strength $\sigma_{d}$ with strain rate $\dot{\varepsilon}$ and temperature $T$. In Figure 4(a), as $\dot{\varepsilon}$ increased, $\sigma_{d}$ increased gradually. As $T$ increased, $\sigma_{d}$ tended to go up first and then decreased gradually. In order to more vividly show effects of $\dot{\varepsilon}$ and $T$ on dynamic peak strength, variation curves of $\sigma_{d}$ with the single variable were given in Figures 4(b) and 4(d). To discuss the effects of temperature on each dynamic mechanical index at a fixed strain rate, the fitting equation between each mechanical index and strain rate was obtained by calculation. Based on the fitting equation, the fitting values of each mechanical index were obtained at a specific strain rate. In this paper, the strain rate of the sandstone sample was concentrated between $60 \mathrm{~s}^{-1}$ and $240 \mathrm{~s}^{-1}$. Therefore, the fitting values of mechanical indexes were calculated under five strain rates of $90 \mathrm{~s}^{-1}$, $120 \mathrm{~s}^{-1}, 150 \mathrm{~s}^{-1}, 180 \mathrm{~s}^{-1}$, and $210 \mathrm{~s}^{-1}$ to study the effects of temperature, as shown in Figure 4(d).

Figure 4(b) indicated that $\sigma_{d}$ increased linearly with $\dot{\varepsilon}$ at various $T$, exhibiting an obvious strain rate effect. Compared with $S_{\sigma}$, the slope value of the fitting curve, the change law of strain rate sensitivity of $\sigma_{d}$ with temperature could be quantitatively analyzed. As shown in Figure $4(\mathrm{c})$, at $25^{\circ} \mathrm{C}, S_{\sigma}$ was 


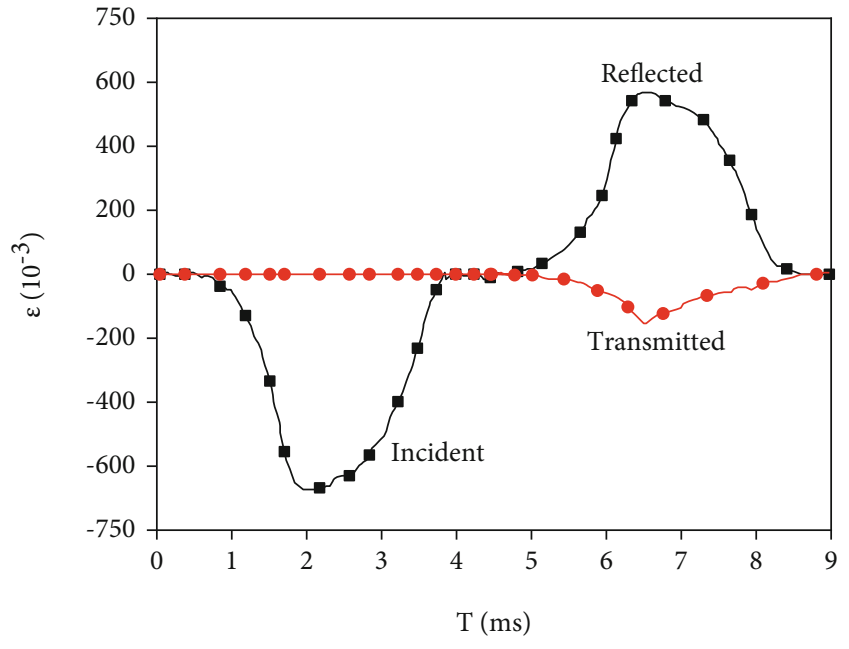

(a) Original waveform

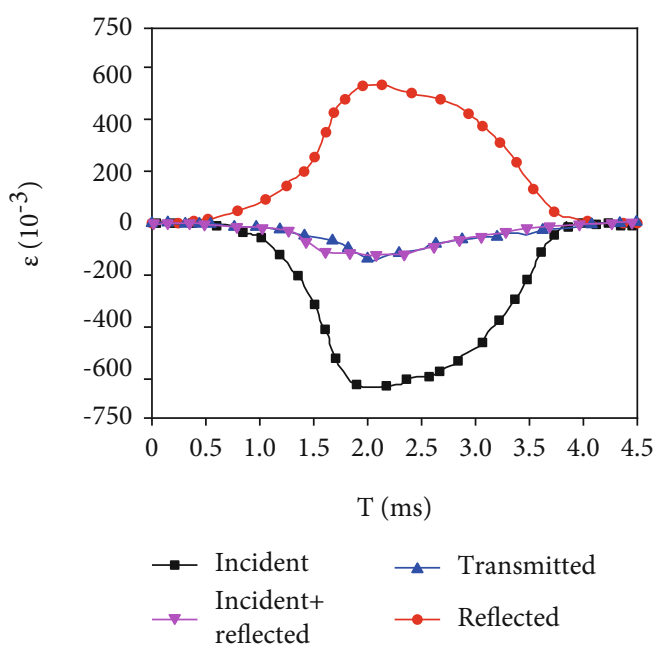

(b) Dynamic stress equilibrium in SHPB test

FIgURE 2: Dynamic stress equilibrium check for a typical test with pulse shaper.

0.158 , and with the increase of temperature from 100 to $800^{\circ} \mathrm{C}, S_{\sigma}$ was $0.216,0.184,0.219,0.276$, and 0.252 , respectively. Compared with room temperature, the range of variation reached $36.70 \%, 16.45 \%, 38.60 \%, 74.68 \%$, and $59.49 \%$. When the temperature reached $600^{\circ} \mathrm{C}, S_{\sigma}$ reached the maximum value of 0.276 .

As shown in Figure $4(\mathrm{~d})$, when $25^{\circ} \mathrm{C} \leq \mathrm{T} \leq 100^{\circ} \mathrm{C}, \sigma_{d}$ was largely unchanged. When $100^{\circ} \mathrm{C} \leq T \leq 400^{\circ} \mathrm{C}, \sigma_{d}$ increased with temperature. When $T \geq 400^{\circ} \mathrm{C}, \sigma_{d}$ decreased with the increase of temperature. Quantitatively, the curve of $150 \mathrm{~s}^{-1}$ was taken as an example, the values of $\sigma_{d}$ under various temperatures were $78.22 \mathrm{MPa}, \quad 78.98 \mathrm{MPa}, \quad 93.91 \mathrm{MPa}$, 106.54 MPa, 88.71 MPa, and 69.91 MPa, respectively. Compared with room temperature, the ranges of variation reached $0.97 \%, 19.87 \%, 36.00 \%, 13.24 \%$, and $-10.76 \%$. When $200^{\circ} \mathrm{C} \leq T \leq 600^{\circ} \mathrm{C}, \sigma_{d}$ was greater than that at room temperature, indicating that temperature had some strengthening effect on $\sigma_{d}$, and the effect was the most significant at $400^{\circ} \mathrm{C}$. The $\sigma_{d}$ at $800^{\circ} \mathrm{C}$ was less than that at room temperature, indicating that there was a weakening effect.

3.3. Variation Laws of Sandstone Dynamic Peak Strain with Temperature and Strain Rate. Figure 5 reveals the change laws of dynamic peak strain $\varepsilon_{d}$ with strain rate $\dot{\varepsilon}$ and temperature $T$. As shown in Figure 5, as $\dot{\varepsilon}$ and $T$ increased, $\varepsilon_{d}$ increased gradually. To more vividly show the effects of $\dot{\varepsilon}$ and $T$ on $\varepsilon_{d}$, the variation curves of $\varepsilon_{d}$ with the single variable were given in Figures 5(b) and 5(d) (similar to dynamic compressive strength, the dynamic peak strain at a specific strain rate was calculated by fitting).

Figure 5(b) indicated that $\varepsilon_{d}$ increased linearly with $\dot{\varepsilon}$ at various $T$, which exhibited obvious strain rate effects. Compared to $S_{\varepsilon}$, the slope value of the fitting curve, the change laws of stain rate sensitivity of $\varepsilon_{d}$ with temperature could be quantitatively analyzed. As shown in Figure 5(c), as the temperature increased, $S_{\varepsilon}$ increased firstly then decreased and increased again finally. At $25^{\circ} \mathrm{C}, S_{\varepsilon}$ was 0.0191 . With the increase of temperature from 100 to $800^{\circ} \mathrm{C}$, the values of $S_{\varepsilon}$ were $0.0234,0.0176,0.0118,0.0276$, and 0.0340 , respectively. Compared with room temperature, the ranges of variation reached $22.51 \%,-7.85 \%,-38.22 \%, 44.50 \%$, and $77.49 \%$. When the temperature reached $800^{\circ} \mathrm{C}, S_{\varepsilon}$ reached the maximum of 0.0340 .

As shown in Figure $5(\mathrm{~d})$, at various $\dot{\varepsilon}$, the $\varepsilon_{d}$ increased gradually with the increase of $T$. When $T$ increased from $25^{\circ} \mathrm{C}$ to $100^{\circ} \mathrm{C}, \varepsilon_{d}$ increased significantly; when $T$ continued to rise to $600^{\circ} \mathrm{C}, \varepsilon_{d}$ increased slightly, indicating that $T$ had little effect on $\varepsilon_{d}$ at this stage. As $T$ rose from $600^{\circ} \mathrm{C}$ to $800^{\circ} \mathrm{C}, \varepsilon_{d}$ increased rapidly. Quantitatively, the curve of $150 \mathrm{~s}^{-1}$ was taken as the research object, $\varepsilon_{d}$ under various temperatures was $0.00673,0.00860,0.00984,0.01097$, 0.01227 , and 0.01603 , respectively. Compared with room temperature, the ranges of variation reached $27.79 \%$, $46.21 \%, 63.00 \%, 82.32 \%$, and $138.18 \%$. When $100^{\circ} \mathrm{C} \leq \mathrm{T} \leq$ $800^{\circ} \mathrm{C}, \varepsilon_{d}$ was greater than that at room temperature, indicating that temperature had some strengthening effect on $\varepsilon_{d}$, and the effect was the most significant at $800^{\circ} \mathrm{C}$.

3.4. Variation Laws of Sandstone Dynamic Elastic Modulus with Temperature and Strain Rate. Figure 6 reveals the change laws of dynamic elastic modulus $E_{d}$ with strain rate $\dot{\varepsilon}$ and temperature $T$. In Figure 6(a), the dynamic elastic modulus fluctuated under the effects of strain rate and temperature. Figure 6(b) shows the variation laws of $E_{d}$ with $\dot{\varepsilon}$. $E_{d}$ varied greatly with $\dot{\varepsilon}$ under different temperatures and did not occur obvious linear characteristics. Therefore, it was hard to obtain the $E_{d}$ at a specific strain rate by linear fitting. At $25^{\circ} \mathrm{C}, 200^{\circ} \mathrm{C}$, and $400^{\circ} \mathrm{C}$, as $\dot{\varepsilon}$ increased, $E_{d}$ tended to increase; at $100^{\circ} \mathrm{C}, E_{d}$ showed a v-shaped trend with the increase of $\dot{\varepsilon}$; at $600^{\circ} \mathrm{C}, E_{d}$ first decreased, then increased, and finally decreased again with the increase of $\dot{\varepsilon}$; at $800^{\circ} \mathrm{C}$, the $E_{d}-\dot{\varepsilon}$ curve was approximately inverted v-shaped.

The variation trend of $E_{d}$ of sandstones with temperature could be preliminary analyzed based on relative positions of $E_{d}-\dot{\varepsilon}$ curves between different temperatures in Figure 6(b). As $T$ increased, $E_{d}$ decreased gradually. 

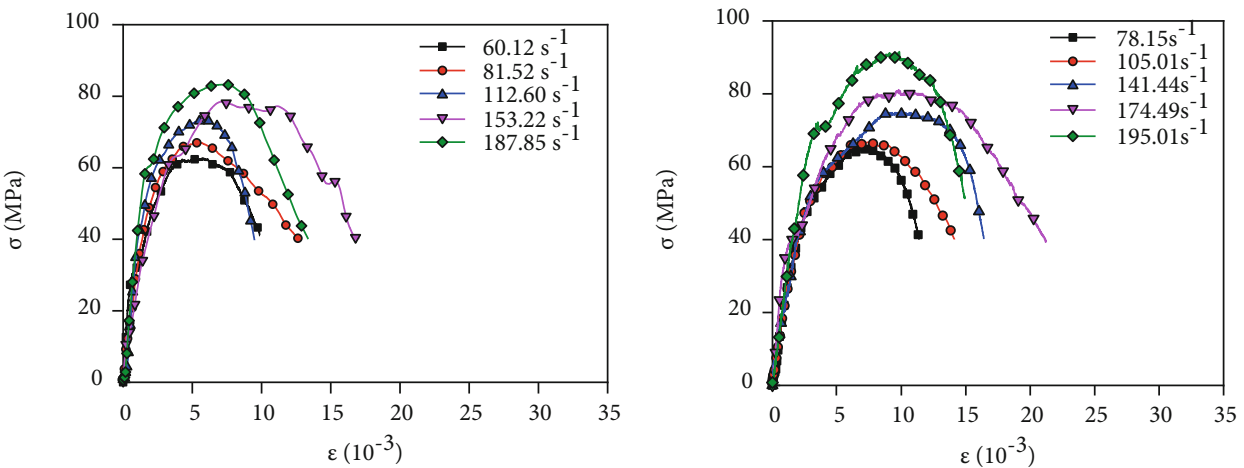

(i) $25^{\circ} \mathrm{C}$
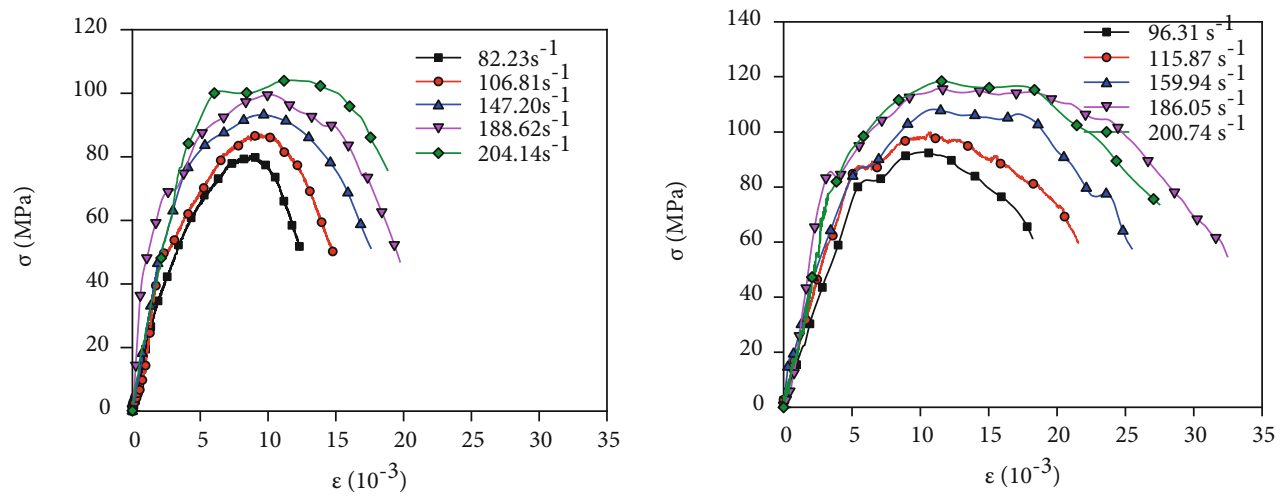

(iii) $200^{\circ} \mathrm{C}$

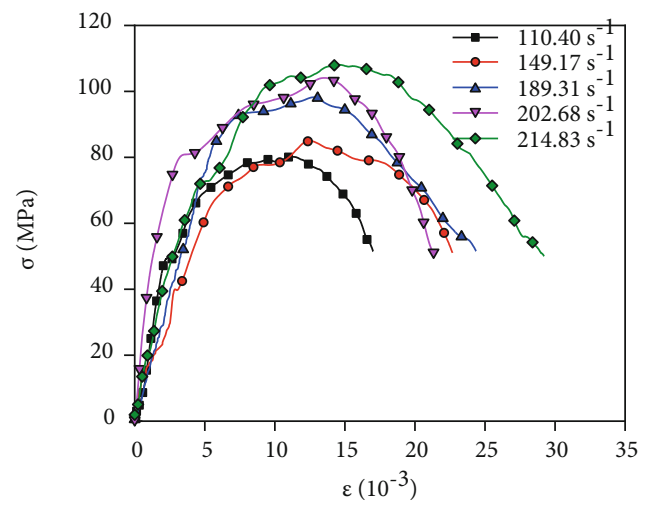

(iv) $400^{\circ} \mathrm{C}$

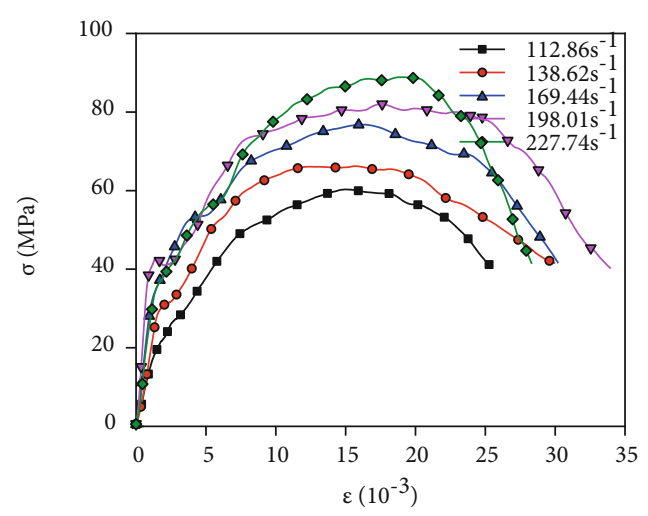

(v) $600^{\circ} \mathrm{C}$

(vi) $800^{\circ} \mathrm{C}$

(a) Stress-strain curve at the same temperature and different strain rates

FIgure 3: Continued. 


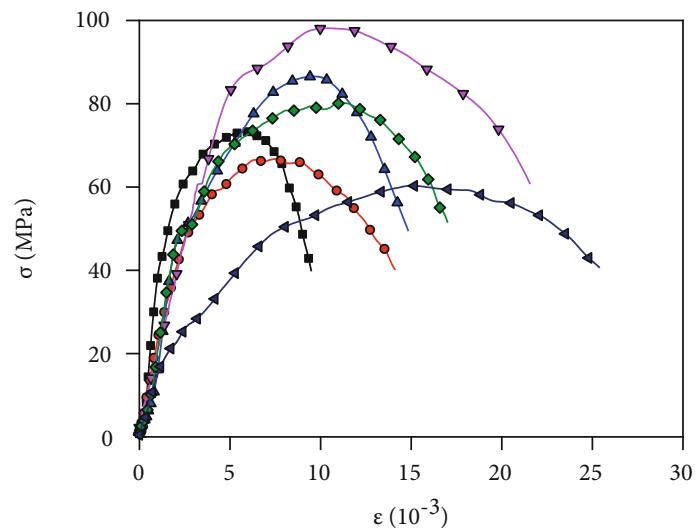

(i) $110 \mathrm{~s}^{-1}$

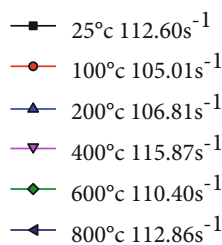

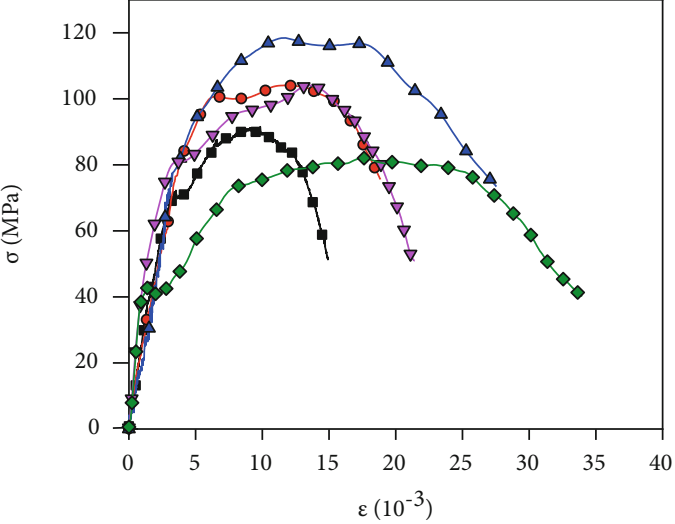

(ii) $198 \mathrm{~s}^{-1}$

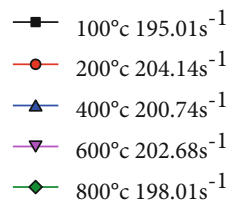

(b) Stress-strain curve at different temperatures and the same strain rates

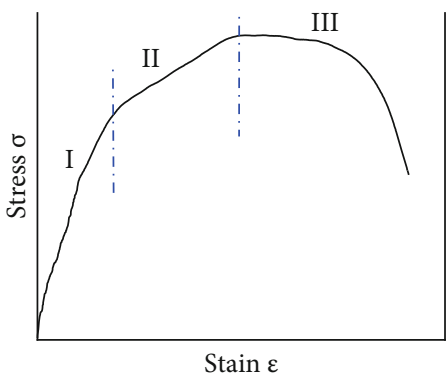

(c) The typical stress-strain curve

FIGURE 3: Stress-strain curves of sandstones under various conditions.

Specifically, when $T$ increased from $25^{\circ} \mathrm{C}$ to $100^{\circ} \mathrm{C}, E_{d}$ decreased significantly. There were no obvious variations in $E_{d}$ between $100^{\circ} \mathrm{C}$ and $400^{\circ} \mathrm{C}$. When $T$ continued to rise to $600^{\circ} \mathrm{C}, E_{d}$ decreased slightly. At $800^{\circ} \mathrm{C}$, it dropped significantly.

\section{Dynamic Macroscopic Failure Characteristics and Energy Dissipation Mechanism of Sandstones under Real-Time High Temperature}

Input energy plays a significant role in characteristics of macroscopic failure and energy dissipation. Therefore, the loading speed was used as the impact loading variable to analyze failure characteristics of sandstones and energy dissipation characteristics in the failure process in this section.

4.1. Macroscopic Failure Characteristics of Sandstones under Different Conditions. The failure modes of sandstones under various temperatures and loading speeds were given, as shown in Table 3. In order to quantitatively describe macro- scopic failure characteristics, fractal dimension $D_{f}$ was used as an analysis parameter [37].

The fractal dimension of rock fragments can be represented as [38]:

$$
\begin{gathered}
D_{f}=3-d, \\
d=\frac{\lg \left(M_{R} / M\right)}{\lg R},
\end{gathered}
$$

where $D_{f}$ is the fractal dimension of samples after impact, $d$ is the slope of the linearly fitting curve in logarithm coordinate system $\left(\lg \left(M_{R} / M\right)-\lg R\right), M_{R}$ is cumulative mass of fragments which is smaller than partial size $R, M$ is the original mass of the sample, and $R$ is the particle size.

Standard sieves with hole sizes of $4,6,8.5,11,13$, and $15 \mathrm{~mm}$ were adopted, and fragments of samples were sieved into six grades. Then, the mass of the fragments of each grade was obtained by high-precision electronic balance, and the fractal dimension of sandstone samples was calculated after impact under different conditions. Figure 7 reveals the variation of fractal dimension $D_{f}$ with 
TABLE 2: Parameters of sandstone mechanical properties under different conditions.

\begin{tabular}{|c|c|c|c|c|c|c|}
\hline $\begin{array}{l}\text { Temperature } \\
\left({ }^{\circ} \mathrm{C}\right)\end{array}$ & $\begin{array}{c}\text { Air pressure } \\
(\mathrm{MPa})\end{array}$ & $\begin{array}{c}\text { Loading speed } \\
(\mathrm{m} / \mathrm{s})\end{array}$ & $\begin{array}{c}\text { Strain rate } \\
\left(\mathrm{s}^{-1}\right)\end{array}$ & $\begin{array}{c}\text { Dynamic peak stress } \\
(\mathrm{MPa})\end{array}$ & $\begin{array}{c}\text { Dynamic peak strain } \\
\left(10^{-3}\right)\end{array}$ & $\begin{array}{c}\text { Dynamic elastic modulus } \\
(\mathrm{GPa})\end{array}$ \\
\hline \multirow{5}{*}{25} & 0.3 & 5.6 & 60.12 & 63.22 & 5.145 & 25.51 \\
\hline & 0.4 & 6.6 & 81.52 & 67.58 & 5.301 & 25.87 \\
\hline & 0.5 & 7.6 & 112.60 & 74.16 & 5.822 & 26.26 \\
\hline & 0.6 & 8.6 & 153.22 & 78.45 & 7.127 & 23.24 \\
\hline & 0.7 & 9.6 & 187.85 & 83.94 & 7.308 & 28.12 \\
\hline \multirow{5}{*}{100} & 0.3 & 5.6 & 78.15 & 65.55 & 7.158 & 18.05 \\
\hline & 0.4 & 6.6 & 105.01 & 66.72 & 7.512 & 18.18 \\
\hline & 0.5 & 7.6 & 141.44 & 74.82 & 8.932 & 16.58 \\
\hline & 0.6 & 8.6 & 174.49 & 81.12 & 9.783 & 15.60 \\
\hline & 0.7 & 9.6 & 195.01 & 91.57 & 9.840 & 20.13 \\
\hline \multirow{5}{*}{200} & 0.3 & 5.6 & 82.23 & 80.29 & 8.648 & 14.23 \\
\hline & 0.4 & 6.6 & 106.81 & 87.09 & 9.217 & 14.35 \\
\hline & 0.5 & 7.6 & 147.20 & 93.21 & 9.567 & 19.95 \\
\hline & 0.6 & 8.6 & 188.62 & 99.55 & 10.223 & 21.24 \\
\hline & 0.7 & 9.6 & 204.14 & 105.16 & 11.160 & 21.21 \\
\hline \multirow{5}{*}{400} & 0.3 & 5.6 & 96.31 & 92.70 & 10.403 & 14.45 \\
\hline & 0.4 & 6.6 & 115.87 & 99.97 & 10.550 & 17.24 \\
\hline & 0.5 & 7.6 & 159.94 & 108.22 & 10.976 & 17.47 \\
\hline & 0.6 & 8.6 & 186.05 & 115.71 & 11.400 & 19.15 \\
\hline & 0.7 & 9.6 & 200.74 & 118.45 & 11.644 & 19.38 \\
\hline \multirow{5}{*}{600} & 0.3 & 5.6 & 110.40 & 80.18 & 11.222 & 16.20 \\
\hline & 0.4 & 6.6 & 149.17 & 85.34 & 12.520 & 12.17 \\
\hline & 0.5 & 7.6 & 189.31 & 98.23 & 12.750 & 15.01 \\
\hline & 0.6 & 8.6 & 202.68 & 104.70 & 13.311 & 18.09 \\
\hline & 0.7 & 9.6 & 214.83 & 108.08 & 14.651 & 14.28 \\
\hline \multirow{5}{*}{800} & 0.3 & 5.6 & 112.86 & 60.31 & 14.945 & 6.52 \\
\hline & 0.4 & 6.6 & 138.62 & 66.23 & 15.708 & 9.29 \\
\hline & 0.5 & 7.6 & 169.44 & 76.79 & 16.366 & 12.63 \\
\hline & 0.6 & 8.6 & 198.01 & 82.03 & 17.580 & 11.48 \\
\hline & 0.7 & 9.6 & 227.74 & 88.88 & 18.919 & 9.80 \\
\hline
\end{tabular}

temperature $T$ and loading speed. As shown in Figure 7(a), the fractal dimension changed slightly with temperature at a higher loading speed. Under a small loading speed, the fractal dimension fluctuated with temperature. The variation curves of $D_{f}$ with the single variable were given in Figures 7(b) and 7(c). As shown in Figure 7(b), the fractal dimension increased with the increase of loading speed at the same temperature, corresponding to Table 3, the damage degree of the sample increased with the increase of loading speed.

(a) When $v \geq 8.6 \mathrm{~m} / \mathrm{s}$, the change of fractal dimension with temperature was smaller than that when $v \leq 7.6 \mathrm{~m} / \mathrm{s}$. This may be because the impact effect was dominant at a higher loading speed, and the temperature had a relatively small effect on the failure process of the sandstone sample. Corresponding to Table 3 , when $v \geq 8.6 \mathrm{~m} / \mathrm{s}$, except for 1 to 3 large fragments at $400^{\circ} \mathrm{C}$ and $600^{\circ} \mathrm{C}$, the damage degree of the sample did not change much with the increase of temperature

(b) When $v \leq 7.6 \mathrm{~m} / \mathrm{s}$, the variation trend of fractal dimension with temperature was similar under different loading speeds. When the temperature increased from $25^{\circ} \mathrm{C}$ to $200^{\circ} \mathrm{C}$, the fractal dimension changed little. When the temperature continued to rise to $400^{\circ} \mathrm{C}$, the fractal dimension decreased significantly. Corresponding to Table 3, when $T \leq 200^{\circ} \mathrm{C}$, the overall damage degree of sandstone samples had little change. When $T$ reached $400^{\circ} \mathrm{C}$, the fragment size increased significantly, probably due to the closure of some original microcracks and microvoids in the sandstone under the effect of temperature [39].

\subsection{Energy Dissipation Characteristics of Sandstone Failure} Process. Based on the one-dimensional stress wave theory, the incident energy, the reflected energy, and the transmitted 

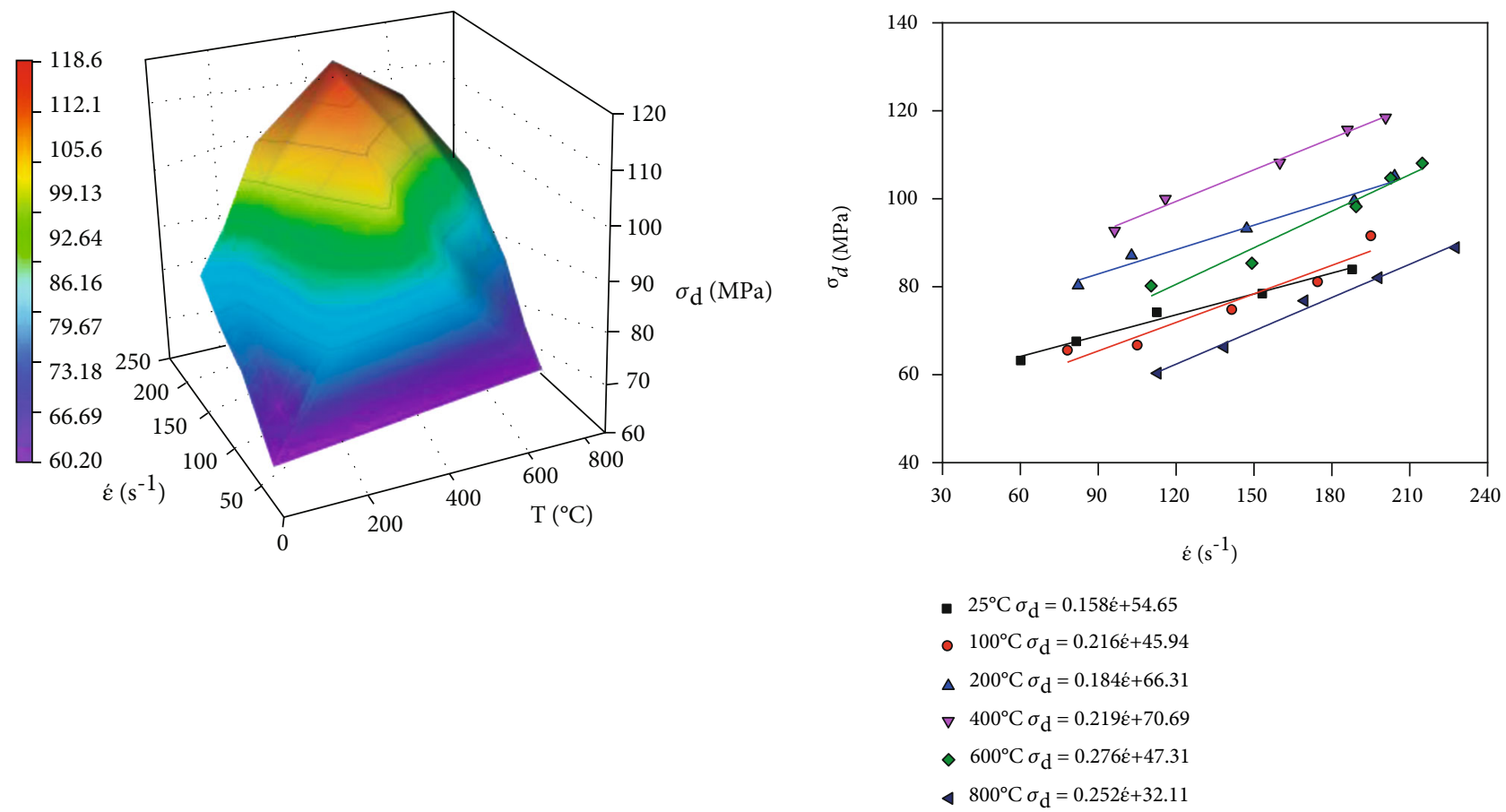

(a) Varying surface of dynamic peak strength with strain rate and temperature

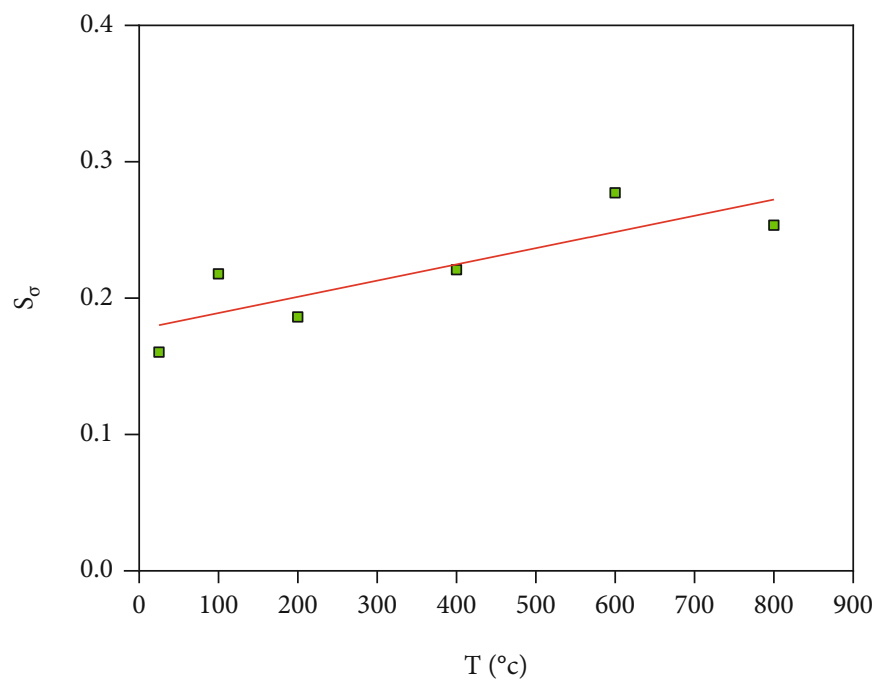

(b) Variation law of dynamic peak strength with strain rate

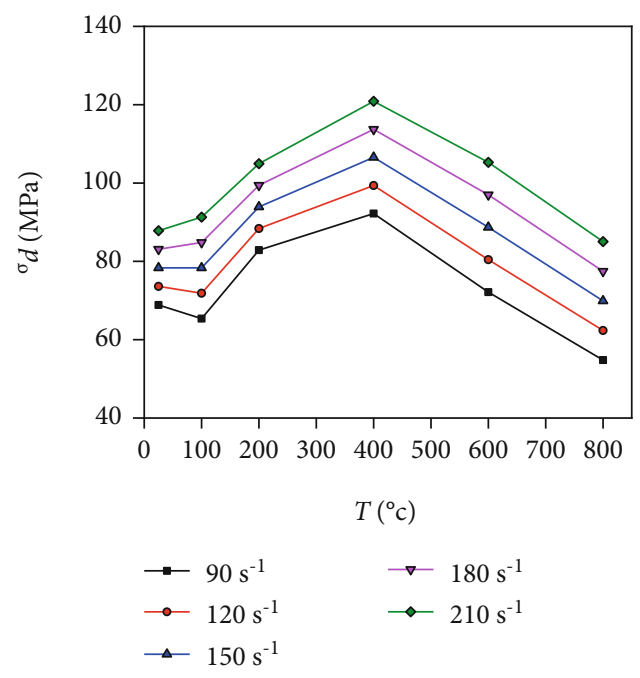

(c) Variation law of the slope value of the fitting curve with temperature

(d) Variation law of dynamic peak strength with temperature

FIgURE 4: Variation law of dynamic peak strength $\sigma_{d}$ with strain rate $\dot{\varepsilon}$ and temperature $T$.

energy during a SHPB test were given by [40]:

$$
\begin{gathered}
W_{I}=\operatorname{ACE} \int_{0}^{t} \varepsilon_{i}^{2}(t) d t, \\
W_{R}=\operatorname{ACE} \int_{0}^{t} \varepsilon_{r}^{2}(t) d t, \\
W_{T}=\operatorname{ACE} \int_{0}^{t} \varepsilon_{t}^{2}(t) d t,
\end{gathered}
$$

where $W_{I}, W_{R}$, and $W_{T}$ denote the incident energy, reflected energy, and transmitted energy, respectively; and $A$ denotes the cross-section area of the bar; $C$ denotes the wave velocity of the bar; $E$ denotes the elastic modulus of the bar and subscripts $i, r$, and $t$ are the incident, reflected, and transmitted wave, respectively.

The sample surfaces, contacted with the incident bar and the transmitted bar, were coated with petroleum jelly and talc powder for lubrication. Therefore, the energy loss by the friction between the sample and the end of the bars during impact could be ignored. According to formulas (3), (4), 


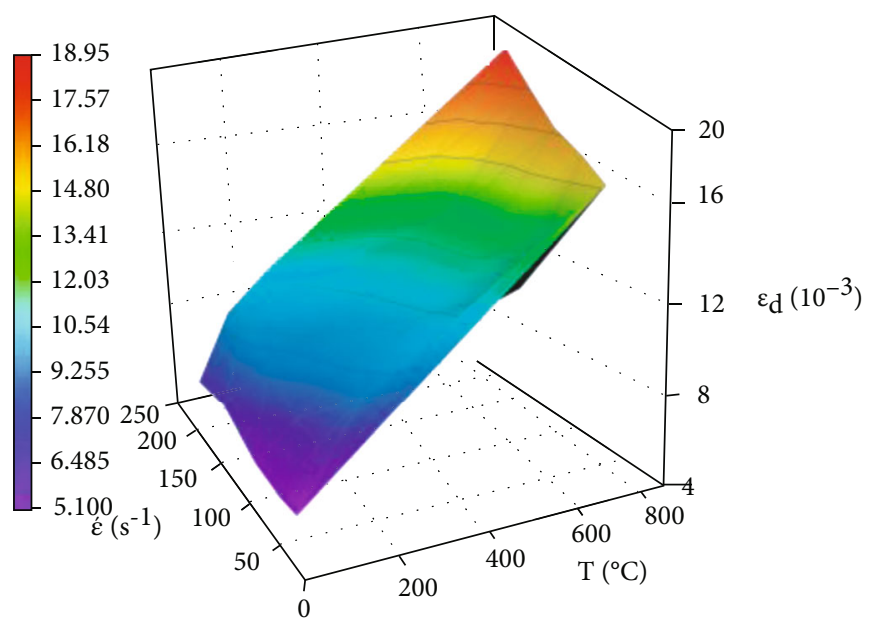

(a) Varying surface of dynamic peak strain with strain rate and temperature

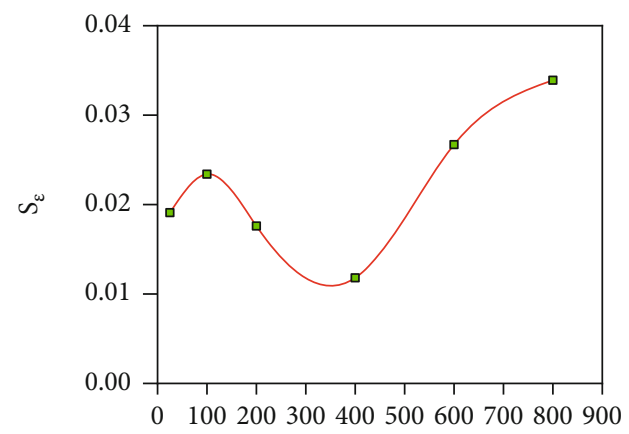

$T\left({ }^{\circ} \mathrm{C}\right)$

(c) Variation law of the slope value of the fitting $S_{\varepsilon}$ with temperature

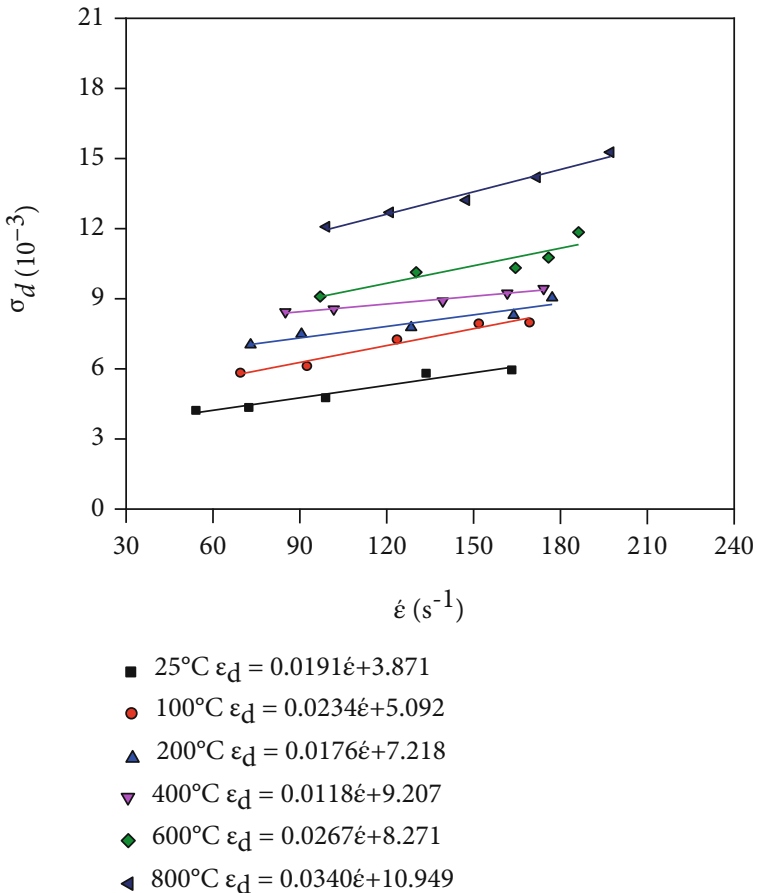

(b) Variation law of dynamic peak strain with strain rate

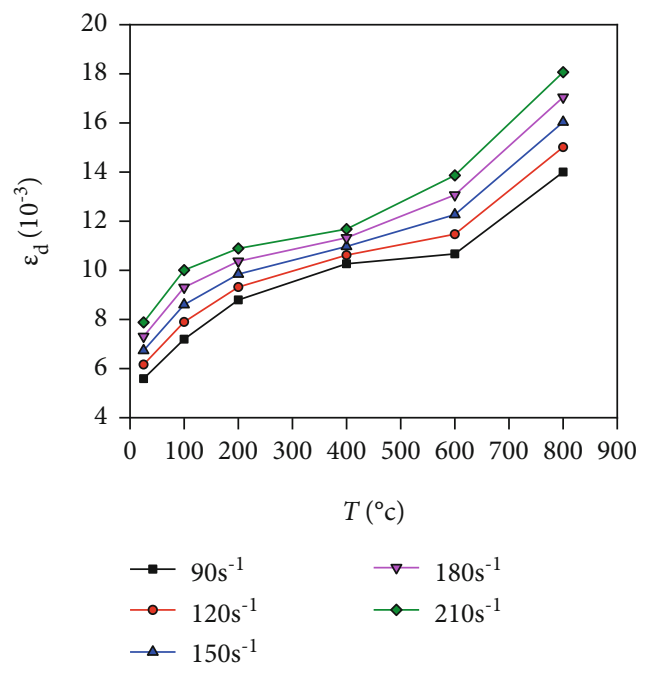

(d) Variation law of dynamic peak strain with temperature

FIGURE 5: Variation law of dynamic peak strain $\varepsilon_{d}$ with strain rate $\dot{\varepsilon}$ and temperature $T$.

and (5), the dissipated energy, $W_{L}$, can be expressed as

$$
W_{L}=W_{I}-W_{R}-W_{T} .
$$

The energy that caused rock fragmentation accounted for about $95 \%$ of the dissipated energy [41]. It can be approximated as the dissipated energy of the sample during the impact process of being converted into the crashing energy:

$$
W_{\mathrm{FD}} \approx W_{L}
$$

To eliminate the influence of the size effect on the energy dissipation characteristics, the energy dissipation density $\rho_{\mathrm{FD}}$ was introduced:

$$
\rho_{\mathrm{FD}}=\frac{W_{\mathrm{FD}}}{V_{s}},
$$

where $V_{s}$ denotes the volume of the sandstone sample, and $\rho_{\mathrm{FD}}$ denotes the energy dissipation density.

The variation laws of sandstone sample energy dissipation $\rho_{\mathrm{FD}}$ with loading speed $v$ and temperature $T$ were calculated, as shown in Figure 8. In Figure 8(a), as the loading speed increased and the temperature decreased, the sample 


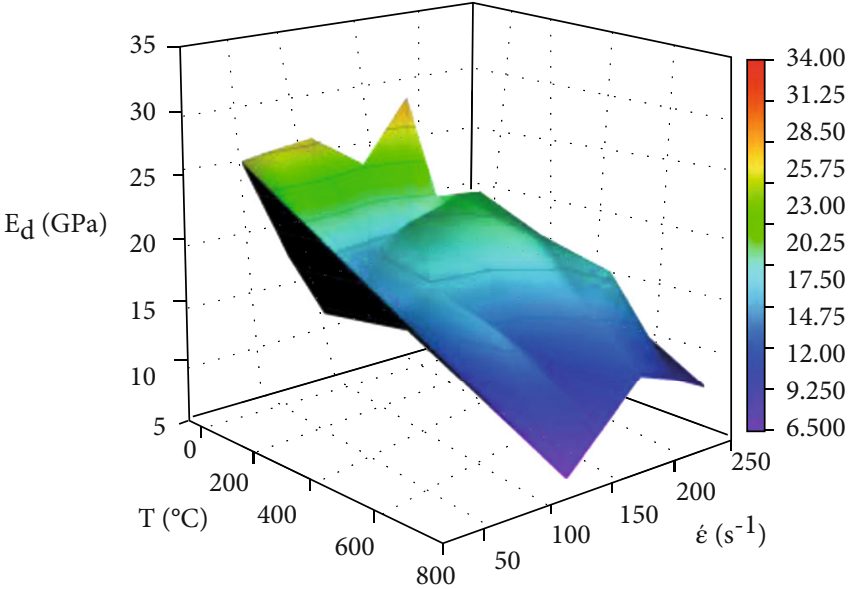

(a) Varying surface of dynamic elastic modulus with strain rate and temperature

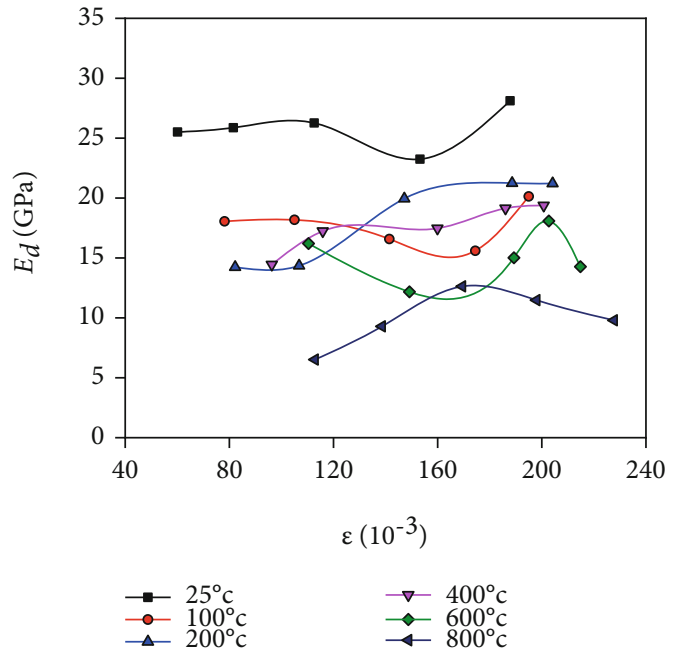

(b) Variation law of dynamic elastic modulus with strain rate

Figure 6: Variation law of dynamic elastic modulus $E_{d}$ with strain rate $\dot{\varepsilon}$ and temperature $T$.

energy dissipation density increased gradually. In order to more vividly show the effects of $v$ and $T$ on $\rho_{\mathrm{FD}}$, the variation curves of $\rho_{\mathrm{FD}}$ with the single variable were given in Figures $8(\mathrm{~b})$ and $8(\mathrm{c})$. Take the sample at $100^{\circ} \mathrm{C}$ in Figure $8(\mathrm{~b})$ as an example, as the loading speed increased, $\rho_{\mathrm{FD}}$ increased gradually. This was mainly because with the increase of loading speed, the initiation, development, and penetration of microcracks inside the sample were more severely during the impact process. In this process, the sample needed to absorb more energy, and the energy dissipation density increased accordingly [42].

Figure 8(c) reveals the variation of energy dissipation density $\rho_{\mathrm{FD}}$ with temperature $T$. Under different loading speeds, the variation trends of energy dissipation density with temperature were similar, as follows:

(a) As the sample temperature increased from $25^{\circ} \mathrm{C}$ to $400^{\circ} \mathrm{C}$ regardless of the loading speed, the energy dissipation density decreased gradually. This was because with the increase of temperature, the expansion of quarts and other mineral particles inside the sample resulted in the closure of partial cracks and pores [43]. Meanwhile, the interparticle cement in the sample was hot melted, the friction force between particles increased [39], and the contact state was improved. Due to the reduction of defects such as cracks and pores and the improvement of contact state between particles, both the number of cracks and the crack propagation process are limited, and the energy dissipation under impact for crack initiation and propagation is reduced [27]

(b) When the sandstone was at $600^{\circ} \mathrm{C}$, the energy dissipation density increased slightly compared with that at $400^{\circ} \mathrm{C}$. As the temperature continued to rise, the thermal melting effect still existed, while the mineral particles continued to expand under the effect of high temperature. Due to varied expansion coeffi- cients, structural thermal stress was generated inside the sandstone [44]. As a result, the number of internal microcracks increased, while the initial cracks expanded and connected [45]. The damage was aggravated, and the dissipated energy also increased in the impact process

(c) When the sample temperature reached $800^{\circ} \mathrm{C}$, the energy dissipation density of the sandstone decreased again. The reason was that some mineral particles and cements in sandstone decomposed at high temperature $[46,47]$. The structure of the sample became loose severely, making the wave impedance ratio decrease. When the incident energy was transmitted to the interface between the specimen and the elastic bar in the form of a wave, most of the energy was reflected back to the incident bar, and the dissipation energy of the sample was reduced

4.3. Variation Law of Fractal Dimension with Energy Dissipation Density. In order to further clarify the relationship between the macroscopic failure of sandstone and energy dissipation under the combined effect of high temperature and impact loading, the relationship between the fractal dimension $D_{f}$ of the fragments after sandstone failure and the energy dissipation density $\rho_{\mathrm{FD}}$ was established, as shown in Figure 9. The fractal dimension increased approximately linearly with the energy dissipation density. This was because the rock failure was the result of the development of macrofracture from the microdamage of the internal structure of sandstone. The more energy the rock absorbed, the more sufficient the crack extended, the higher the degree of fracture, and the greater the value of the fractal dimension $D_{f}$ [48]. When $T \leq 200^{\circ} \mathrm{C}$, the energy density was concentrated between $0.2 \mathrm{~J} \cdot \mathrm{cm}^{-3}$ and $1.2 \mathrm{~J} \cdot \mathrm{cm}^{-3}$, and the fractal dimension was between 2.4 and 2.7. When $T \geq 400^{\circ} \mathrm{C}$, the energy dissipation density was concentrated between 
TABLE 3: Failure modes of the sandstone sample with various high temperatures under different loading speeds.

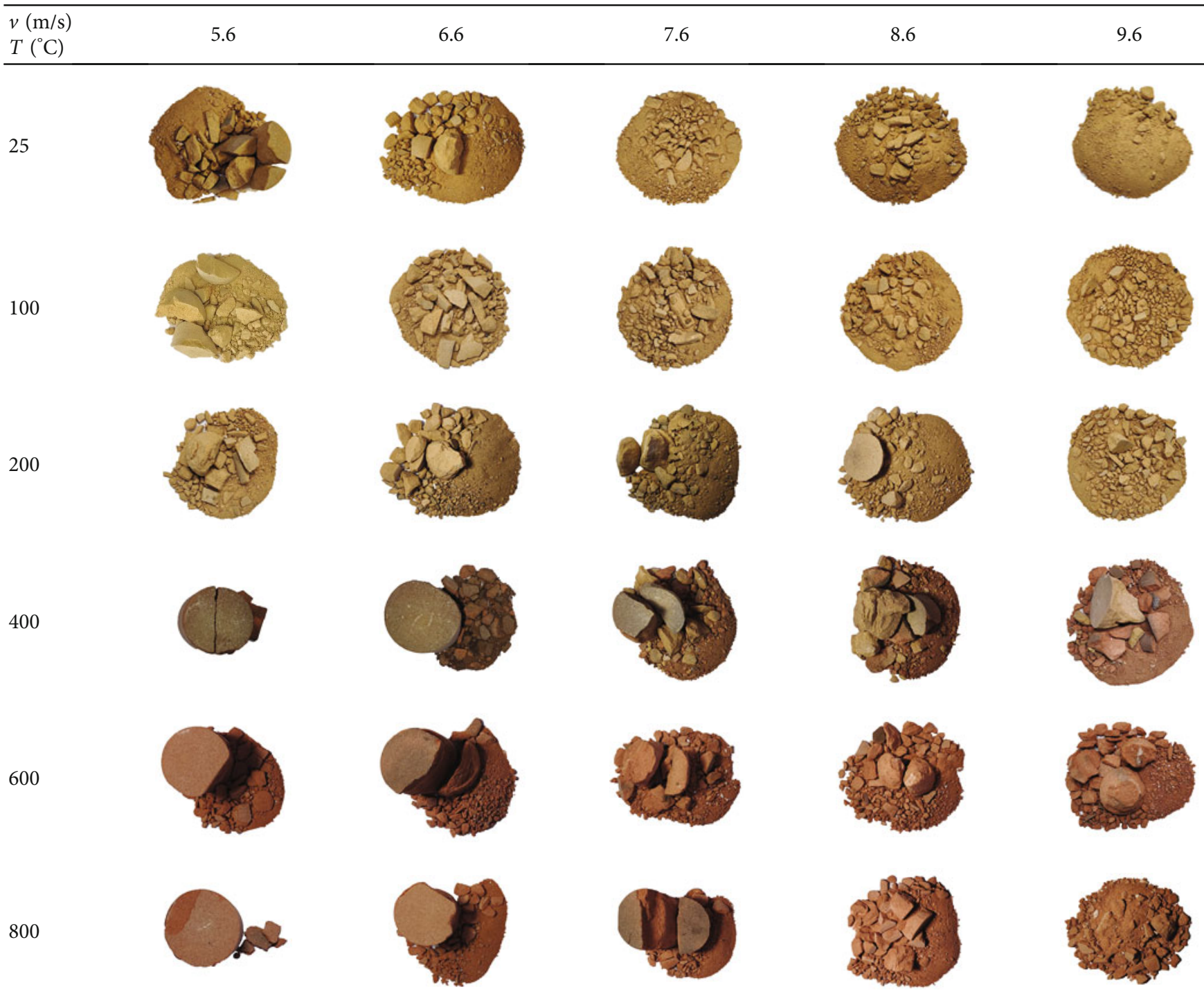

$0.2 \mathrm{~J} \cdot \mathrm{cm}^{-3}$ and $0.6 \mathrm{~J} \cdot \mathrm{cm}^{-3}$, and the fractal dimension was between 2.1 and 2.7. It could be seen that with the increase of temperature, the span of fractal dimension increased, and the span of energy dissipation density decreased. That is, with the increase of temperature, the slope value of the $D_{f-} \rho_{\mathrm{FD}}$ fitting curve increased. It showed that in the case of absorbing unit energy, the higher the temperature of the sample, the greater the fractal dimension changed, and the damage degree of the sample changed more intensely.

\section{Dynamic Mechanical Damage Constitutive Model of Sandstone in High- Temperature Environment}

5.1. Establishing of Constitutive Model of Sandstone. In this paper, the component combination method was applied to establish the dynamic damage constitutive model for rocks under real-time high temperature. First, the model can sum- marize static mechanical properties under conventional conditions and dynamic damage mechanical properties under high temperature. Second, the static mechanical properties persist, and only rigid characteristics exist damage, while viscous characteristics do not exist damage. Finally, thermal effect and dynamic effect are coupled to form the damage body. Based on this thought, the dynamic damage constitutive model of sandstone under real-time high temperature was established, as shown in Figure 10. It was composed of two Kelvin bodies in series. One comprised a linear spring representing inherent static elastic characteristics (Figure 10(a)) and a static viscous body representing the inherent viscous characteristics (Figure 10(b)) in parallel. The other Kelvin body consisted of a damage body (Figure 10(c)) in parallel with a dynamic viscous body (Figure 10(d)) with the consideration of temperature effects and sandstone damage characteristics [49].

Four assumptions were given to determine constitutive equations of the model: 


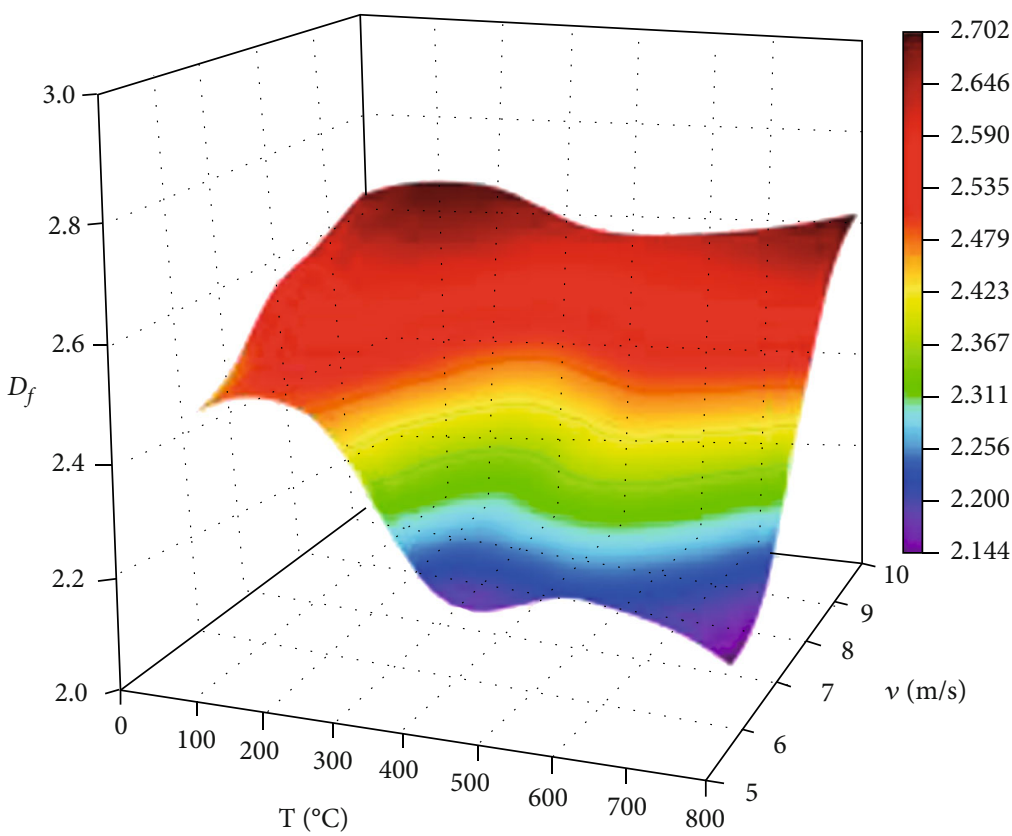

(a) Varying surface of fractal dimension with loading speed and temperature

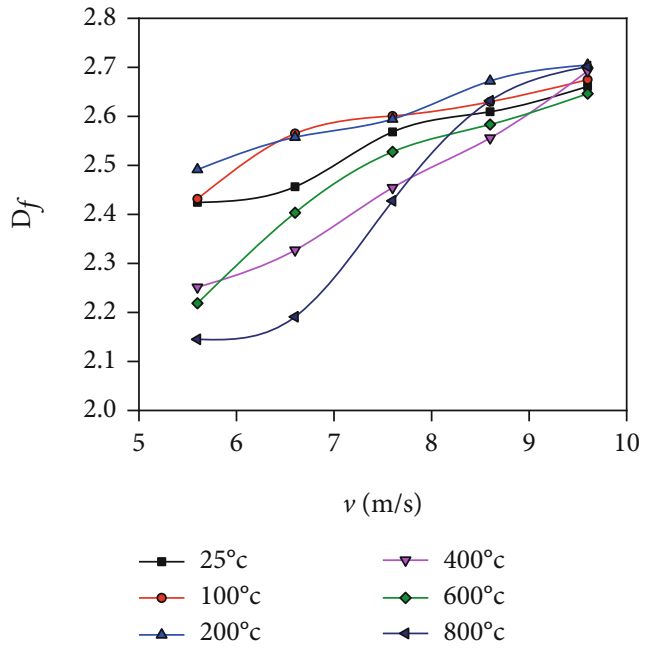

(b) Variation law of fractal dimension with loading speed

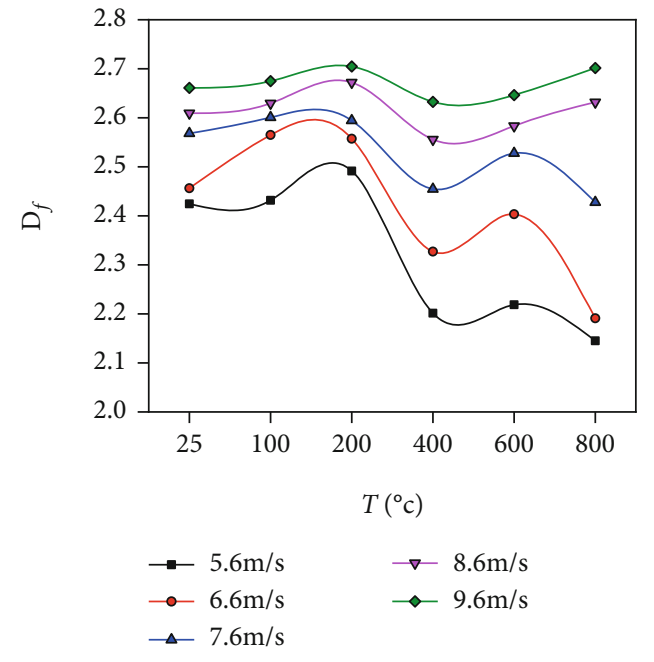

(c) Variation law of fractal dimension with temperature

FIGURE 7: Variation law of fractal dimension $D_{f}$ with loading speed $v$ and temperature $T$.

(a) The size of the microelement body was large enough to contain many defects, and it was sufficiently small and could be regarded as a particle of continuous damage mechanics

(b) The rock was continuous, and its damage was uniform

(c) The strain rate remained unchanged during impact [50]

(d) The strength of the microunits followed the Weibull distribution $[51,52]$

Based on the strain equivalent hypothesis proposed by Lemaitre [53], the relationship between the effective stress of the damage body and the nominal stress is as follows:

$$
\sigma^{*}=\frac{\sigma}{1-D}
$$

where $\sigma^{*}$ denotes the effective stress, $\sigma$ denotes the nominal stress, and $D$ is damage variable, defined as follows [54]:

$$
D=\frac{N_{f}}{N}
$$

where $N_{f}$ denotes the microunits failure under an external load, $N$ denotes the total number of microunits, and $D$ describes the damage degree of the samples, ranging from 


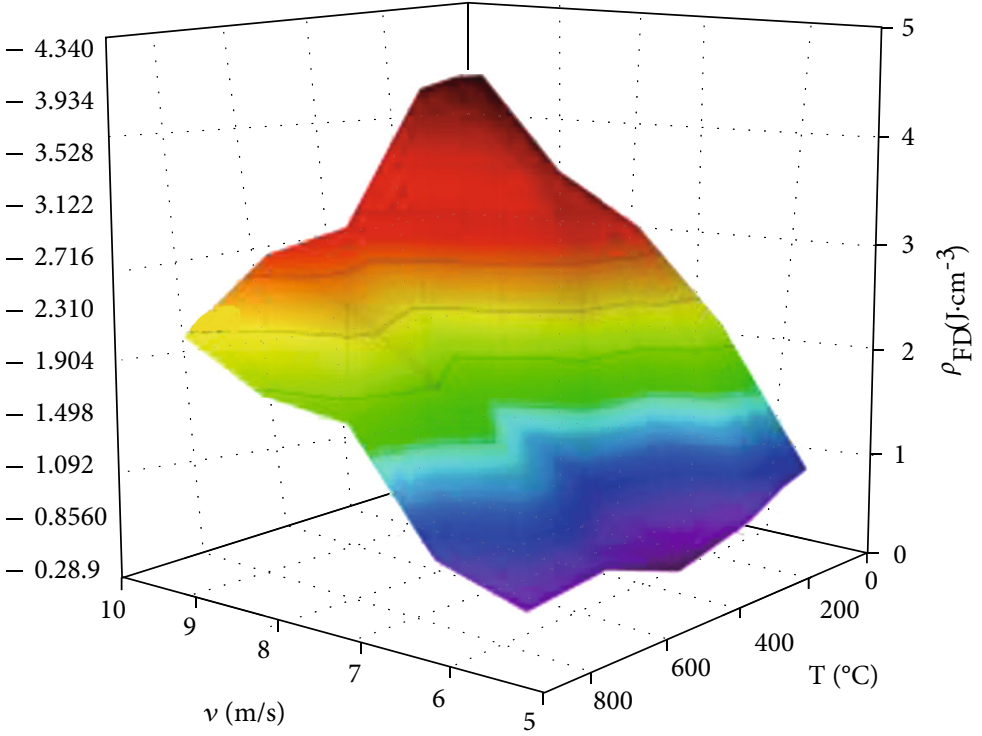

(a) Varying surface of energy dissipation density with loading speed and temperature

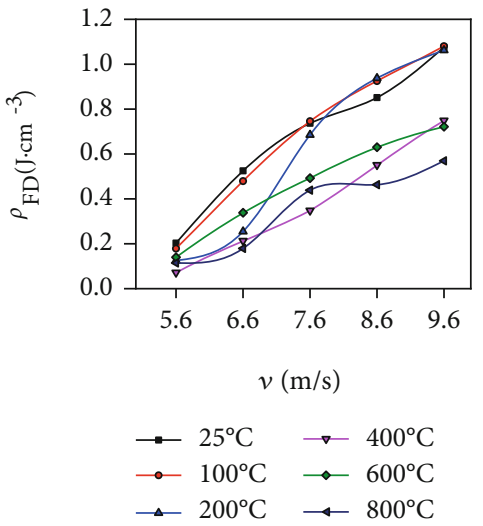

(b) Variation law of energy dissipation density with loading speed

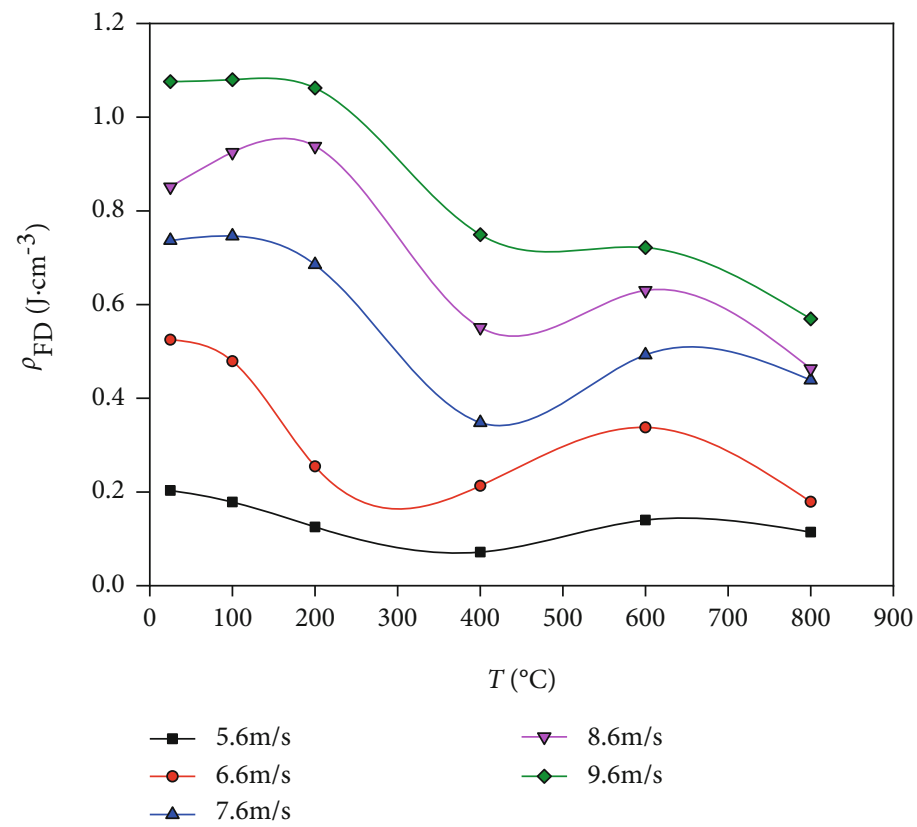

(c) Variation law of energy dissipation density with temperature

FIGURE 8: Variation law of energy dissipation density $\rho_{\mathrm{FD}}$ with loading speed $v$ and temperature $T$.

0 to $1 . D=0$ denotes the intact state of sample, and $D=1$ denotes the damaged state [54].

Combined with the Hooke's law, the stress-strain relationship of the damage body can be obtained as follows:

$$
\varepsilon_{21}=\frac{\sigma^{*}}{k_{D}}=\frac{\sigma_{21}}{k_{D}(1-D)},
$$

where $k_{D}$ denotes the elastic modulus of the damage body, and $\sigma_{21}$ and $\varepsilon_{21}$ denote the stress and strain of the damage body, respectively. From equation (11), the stress-strain rela- tionship can be expressed as

$$
\sigma_{21}=k_{D} \varepsilon_{21}(1-D)
$$

The Kelvin body comprised a viscous body and a damage body in parallel. Based on the parallel rule [50], the stress-strain relationship of Kelvin body II can be obtained as follows:

$$
\sigma_{2}=k_{D} \varepsilon_{21}(1-D)+\eta_{2} \dot{\varepsilon}_{22}
$$

Similarly, the stress-strain relationship of Kelvin body I 


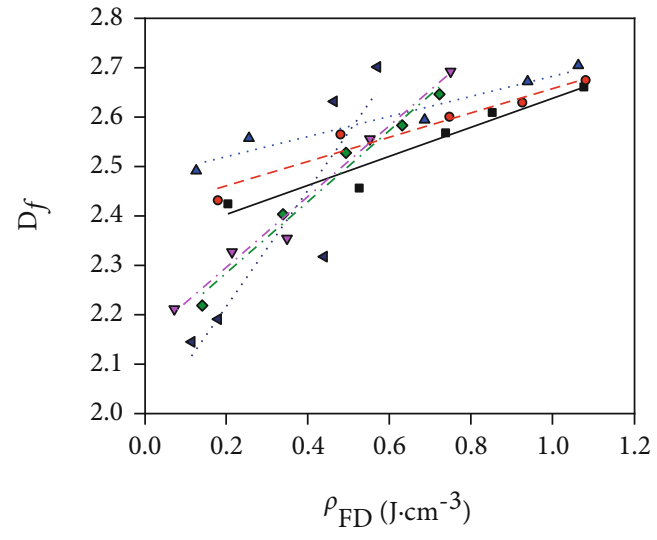

- $25^{\circ} \mathrm{C} D=0.294 p \mathrm{FD}^{+2.345}$

- $100^{\circ} \mathrm{C} D=0.250 p \mathrm{FD}^{+2.410}$

$\triangle 200^{\circ} \mathrm{C} \mathrm{D}=0.204 p \mathrm{FD}^{+2.479}$

$\nabla 400^{\circ} \mathrm{C} D=0.710 p \mathrm{FD}^{+2.154}$

$\diamond 600^{\circ} \mathrm{C} D=0.722 p \mathrm{FD}^{+2.141}$

$\triangleleft 800^{\circ} \mathrm{C} D=1.178 p \mathrm{FD}^{+1.981}$

Figure 9: Variation law of fractal dimension $D_{f}$ with energy dissipation density $\rho_{\mathrm{FD}}$.

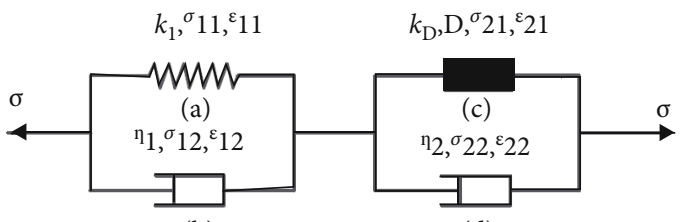

(b)

(d)

FIGURE 10: Sketch of dynamic damage constitutive model of sandstone: (a) linear elastic spring, (b) static viscous body, (c) damage body, and (d) dynamic viscous body.

can be represented as follows:

$$
\sigma_{1}=k_{1} \varepsilon_{11}+\eta_{1} \dot{\varepsilon}_{12}
$$

where $\sigma_{1}$ and $\varepsilon_{1}$ denote the stress and strain of Kelvin body I; $\sigma_{11}$ and $\varepsilon_{11}$ denote the stress and strain of the linear spring, and $k_{1}$ denotes the elastic coefficient; $\sigma_{12}$ and $\varepsilon_{12}$ denote the stress and strain of the static viscous body, and $\eta_{1}$ denotes the viscosity coefficient.

The ordinary differential equations of total stress $\sigma$ and total strain $\varepsilon$ of the constitutive model could be obtained by simultaneous equations (13) and (14):

$\frac{k_{1}+k_{D}(1-D)}{k_{1} k_{D}(1-D)} \sigma+\frac{\eta_{1}+\eta_{2}}{k_{1} k_{D}(1-D)} \dot{\sigma}=\varepsilon+\frac{k_{1} \eta_{2}+k_{D}(1-D) \eta_{1}}{k_{1} k_{D}(1-D)} \dot{\varepsilon}+\frac{\eta_{1} \eta_{2}}{k_{1} k_{D}(1-D)} \ddot{\varepsilon}$.

Based on the assumption (c), $\ddot{\varepsilon}$, the derivative of $\dot{\varepsilon}$, was
TABLE 4: Fitted parameters of the constitutive model.

\begin{tabular}{lcccccccc}
\hline $\begin{array}{l}T \\
\left({ }^{\circ} \mathrm{C}\right)\end{array}$ & $\dot{\varepsilon}\left(\mathrm{s}^{-1}\right)$ & $\begin{array}{c}k_{D} \\
(\mathrm{GPa})\end{array}$ & $e_{T}$ & $\eta_{1}$ & $\begin{array}{c}\eta_{2}\left(10^{-}\right) \\
25\end{array}$ & $\begin{array}{c}e_{0}\left(10^{-}\right. \\
3\end{array}$ & $m$ & $R^{2}$ \\
\hline \multirow{2}{*}{25} & 60.12 & 25.51 & 1.00 & 4.49 & 2.50 & 6.75 & 1.59 & 0.989 \\
& 112.60 & 26.26 & 1.00 & 4.29 & 2.30 & 6.56 & 1.69 & 0.973 \\
& 187.85 & 28.12 & 1.00 & 4.31 & 2.07 & 6.29 & 1.18 & 0.981 \\
\hline \multirow{3}{*}{100} & 78.15 & 18.05 & 0.99 & 4.27 & 2.20 & 9.04 & 1.93 & 0.986 \\
& 141.44 & 16.58 & 0.99 & 4.40 & 3.35 & 11.31 & 1.49 & 0.986 \\
& 195.01 & 20.13 & 0.99 & 4.10 & 3.92 & 11.51 & 1.82 & 0.940 \\
\hline \multirow{3}{*}{200} & 82.23 & 14.23 & 1.09 & 4.66 & 4.22 & 11.10 & 2.56 & 0.994 \\
& 147.20 & 19.95 & 1.09 & 4.26 & 4.09 & 11.47 & 1.62 & 0.994 \\
& 204.14 & 21.21 & 1.09 & 4.35 & 4.52 & 12.66 & 1.41 & 0.959 \\
\hline \multirow{4}{*}{400} & 96.31 & 14.45 & 1.42 & 4.45 & 5.99 & 11.78 & 1.36 & 0.988 \\
& 159.94 & 17.47 & 1.42 & 4.70 & 4.12 & 12.46 & 1.14 & 0.983 \\
& 200.74 & 19.38 & 1.42 & 4.23 & 4.47 & 10.10 & 0.91 & 0.981 \\
\hline \multirow{3}{*}{600} & 110.40 & 16.20 & 1.31 & 4.45 & 4.00 & 9.67 & 1.20 & 0.986 \\
& 189.31 & 15.01 & 1.31 & 4.52 & 4.00 & 13.37 & 1.38 & 0.987 \\
& 214.83 & 14.28 & 1.31 & 4.62 & 4.15 & 15.81 & 1.39 & 0.986 \\
\hline & & & & & & & &
\end{tabular}

zero:

$\frac{k_{1}+k_{D}(1-D)}{k_{1} k_{D}(1-D)} \sigma+\frac{\eta_{1}+\eta_{2}}{k_{1} k_{D}(1-D)} \dot{\sigma}=\varepsilon+\frac{k_{1} \eta_{2}+k_{D}(1-D) \eta_{1}}{k_{1} k_{D}(1-D)} \dot{\varepsilon}$.

After the Laplace transform and Laplace inverse transform of the equation (16),

$$
\begin{aligned}
\sigma= & \frac{k_{1} k_{D}(1-D) \varepsilon+\left(k_{1} \eta_{2}+k_{D}(1-D) \eta_{1}\right) \dot{\varepsilon}}{k_{1}+k_{D}(1-D)} \\
& \cdot\left[1-\exp \left(-\frac{k_{1}+k_{D}(1-D)}{\eta_{1}+\eta_{2}} \cdot t\right)\right] .
\end{aligned}
$$

Based on assumption (c):

$$
\begin{aligned}
\varepsilon & =\dot{\varepsilon} \cdot t, \\
t & =\frac{\varepsilon}{\dot{\varepsilon}} .
\end{aligned}
$$

The basic dynamic constitutive equation of sandstone was obtained by substituting equation (18) into equation (17), as follows:

$$
\begin{aligned}
\sigma= & \frac{k_{1} k_{D}(1-D) \varepsilon+\left(k_{1} \eta_{2}+k_{D}(1-D) \eta_{1}\right) \dot{\varepsilon}}{k_{1}+k_{D}(1-D)} \\
& \cdot\left[1-\exp \left(-\frac{k_{1}+k_{D}(1-D)}{\eta_{1}+\eta_{2}} \cdot \frac{\varepsilon}{\dot{\varepsilon}}\right)\right] .
\end{aligned}
$$

5.2. The Constitutive Model. Based on assumption (d), the strength of microunits obeyed the Weibull distribution, which had a probability density function $P(F)$ as follows 


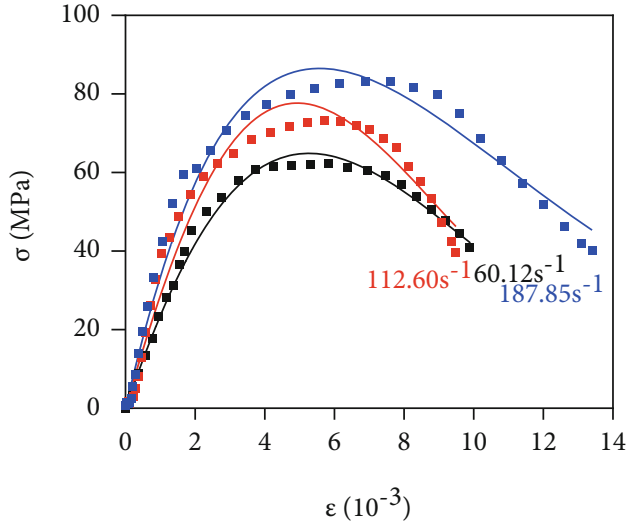

(a) $25^{\circ} \mathrm{C}$

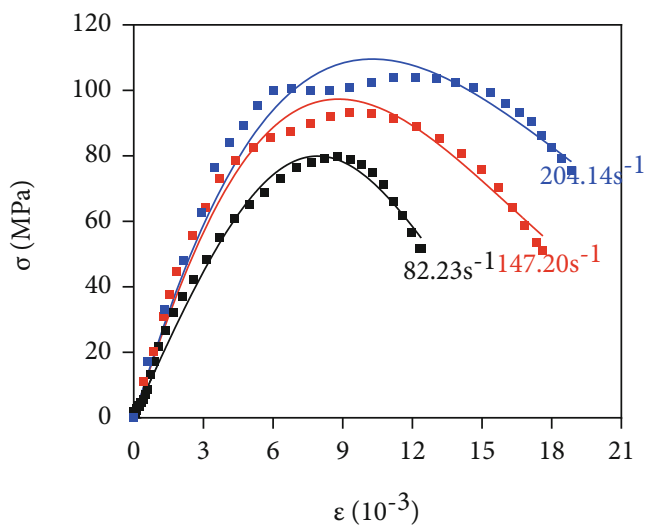

(c) $200^{\circ} \mathrm{C}$

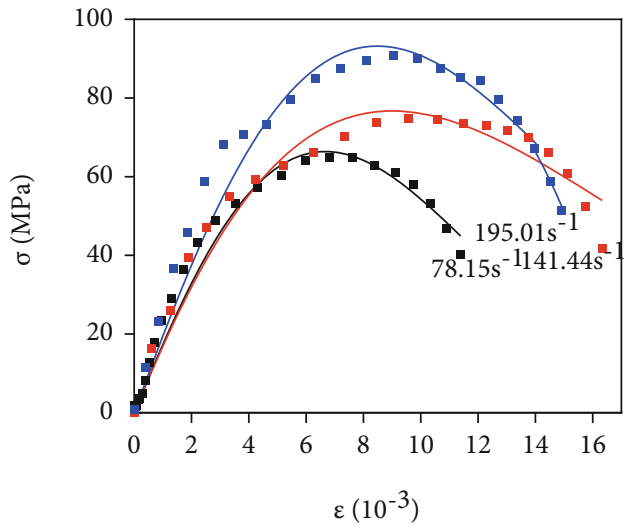

(b) $100^{\circ} \mathrm{C}$

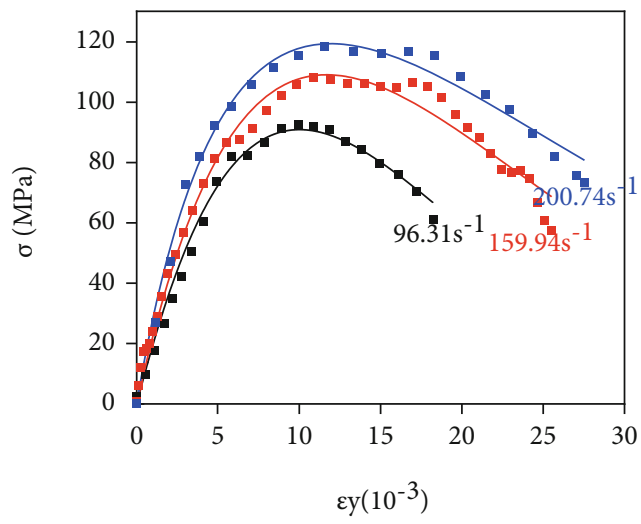

(d) $400^{\circ} \mathrm{C}$

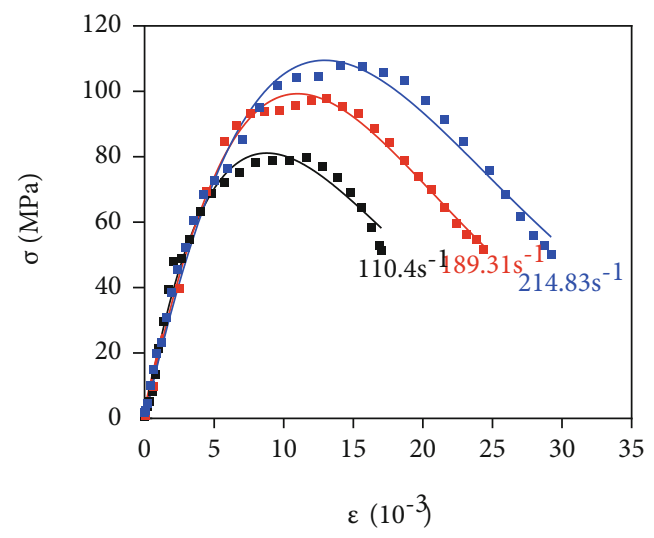

(e) $600^{\circ} \mathrm{C}$

Figure 11: Comparisons of measured and fitted stress-strain curves at different conditions.

[35]:

$$
P(F)=\frac{m}{F_{0}}\left(\frac{F}{F_{0}}\right)^{m-1} \exp \left[-\left(\frac{F}{F_{0}}\right)^{m}\right]
$$

where $F$ denotes the microunit strength and $F_{0}$ is its mean value, and $m$ is the shape parameter.
Based on strain strength theory [32], $F$ can be replaced by strain $\varepsilon$. Therefore, equation (20) can be written as

$$
P(\varepsilon)=\frac{m}{e_{0}}\left(\frac{\varepsilon}{e_{0}}\right)^{m-1} \exp \left[-\left(\frac{\varepsilon}{e_{0}}\right)^{m}\right]
$$

where $e_{0}$ denotes the scale parameter, and $\varepsilon$ denotes the strain of sample. 
Based on equations (10) and (21), D could be expressed as

$$
D=\frac{N_{f}}{N}=\frac{N \int_{0}^{\varepsilon} P(\varepsilon) d \varepsilon}{N}=1-e^{-\left(\varepsilon / e_{0}\right)^{m}} .
$$

According to the above discussions, the internal structure of sandstone was affected by temperature in various degrees, which could be expressed as the variation of the energy dissipation density with temperature macroscopically. Thus, the energy dissipation density was selected as an index to characterize the influence of temperature on mechanical properties of sandstones (among them, the internal structure of sandstone was completely loose at $800^{\circ} \mathrm{C}$, and its energy dissipation density did not have reference values. Thus, this paper only calculated the temperature influence coefficient at $600^{\circ} \mathrm{C}$ and below), as follows:

$$
e_{T}=1-\frac{\rho_{25}-\rho_{\mathrm{T}}}{\rho_{25}}
$$

where $e_{T}$ denotes the temperature influence coefficient, $\rho_{25}$ denotes the average energy dissipation density of sandstone samples at $25^{\circ} \mathrm{C}$, and $\rho_{T}$ denotes the average energy dissipation density at each temperature $\left(100^{\circ} \mathrm{C}, 200^{\circ} \mathrm{C}, 400^{\circ} \mathrm{C}\right.$, and $\left.600^{\circ} \mathrm{C}\right)$.

Substituting the temperature influence coefficient $e_{T}$ and damage variable $D$ into equation (23), the stress-strain relationship of the damage body after considering the temperature effect was obtained as follows:

$$
\sigma_{2}=E \varepsilon_{2}(1-D)=E_{D} e_{T} \varepsilon \exp \left(-\left(\frac{\varepsilon}{e_{0}}\right)^{m}\right)
$$

Correspondingly, the dynamic mechanical damage constitutive equation of sandstone in high-temperature environment can be expressed as

$$
\begin{aligned}
\sigma= & \frac{k_{1} k_{D} e_{T} \varepsilon \exp \left(-\left(\varepsilon / e_{0}\right)^{m}\right) \varepsilon+\left(k_{1} \eta_{2}+k_{D} e_{T} \varepsilon \exp \left(-\left(\varepsilon / e_{0}\right)^{m}\right) \eta_{1}\right) \dot{\varepsilon}}{k_{1}+k_{D} e_{T} \varepsilon \exp \left(-\left(\varepsilon / e_{0}\right)^{m}\right)} \\
& \cdot\left[1-\exp \left(-\frac{k_{1}+k_{D} e_{T} \varepsilon \exp \left(-\left(\varepsilon / e_{0}\right)^{m}\right)}{\eta_{1}+\eta_{2}} \cdot \frac{\varepsilon}{\dot{\varepsilon}}\right)\right] .
\end{aligned}
$$

5.3. Validation of the Constitutive Model. The constitutive model established in this paper contained seven parameters $\left(k_{D}, k_{1}, \eta_{1}, \eta_{2}, \varepsilon_{0}, e_{T}\right.$, and $\left.m\right)$. The parameters could be obtained by fitting the experimental data under various conditions. It could be found by fitting that $k_{D}$ was approximately equal to the dynamic elastic modulus $E_{D}$. To reduce the amount of fitting work and meet the physical significance of the constitutive model, the static elastic modulus $E_{C}$ of sandstone was taken as the elastic coefficient $k_{1}$, and the dynamic elastic modulus $E_{D}$ was taken as the parameter $k_{D}$. The fitting toolbox in Matlab and nonlinear fitting method were adopted to determine the parameters of the constitutive model. The values of various parameters and the correlation coefficient $R^{2}$ are shown in Table 4 , and the fitted and test stress-strain curves are compared in Figure 11. Figure 11 and Table 4 revealed that the test curves were in great agreement with the fitted curves and the correlation coefficient $R^{2}$ ranged from 0.959 to 0.994 , which indicated that the model was suitable for summarizing the dynamic mechanical constitutive relationship of sandstone in high-temperature environment.

\section{Conclusion}

In this paper, the dynamic mechanical properties of sandstone are systematically studied by using the separated Hopkinson pressure bar (HT-SHPB) test system with real-time high-temperature function. Starting from the macroscopic failure characteristics, the fractal dimension and energy dissipation mechanism of sandstones under high temperature were discussed. The dynamic mechanical damage constitutive model of sandstones was established under hightemperature environment. The following conclusions were obtained:

(1) The stress-strain curve of sandstone in hightemperature environment was mainly composed of elastic deformation stage, inelastic deformation stage, and failure stage. When the temperature ranged from $25^{\circ} \mathrm{C}$ to $600^{\circ} \mathrm{C}$, the shape of the sandstone stress-strain curve changed little. After $600^{\circ} \mathrm{C}$, the proportion of elastic deformation stage gradually decreased with the increase of temperature. On the contrary, the proportion of inelastic deformation stage gradually increased

(2) Under the condition of a fixed temperature, the dynamic compressive strength and dynamic peak strain of sandstone increased linearly with the increase of strain rate. Under the condition of a fixed strain rate, as temperature increased, the dynamic compressive strength increased first and then decreased, reaching the maximum at $400^{\circ} \mathrm{C}$, and the dynamic peak strain gradually increased. By comparing the slopes of the fitting curves of dynamic peak stress (peak strain) and strain rate, the strain rate sensitivity of dynamic compressive strength was the smallest at $25^{\circ} \mathrm{C}$, and the maximum was at $800^{\circ} \mathrm{C}$. Dynamic peak strain rate sensitivity was minimum at $400^{\circ} \mathrm{C}$ and maximum at $800^{\circ} \mathrm{C}$. In addition, the dynamic modulus of elasticity did not vary significantly with strain rate and tended to decrease overall with temperature

(3) The influence of temperature on the internal structure of sandstone was a crucial factor that changed macroscopic mechanical characteristics. The mineral particle expansion, structural thermal stress, and thermal decomposition played leading roles under different temperatures. The macroscopically manifested as the variation of failure characteristic and energy dissipation density with temperature. There was a linear relationship between the fractal dimension and the energy dissipation density. As the 
temperature increased, the slope of the fractal dimension-energy dissipation density fitting curve gradually increased

(4) According to mechanical properties of sandstones under high temperature, four assumptions were proposed in sandstone impact failure. Based on the principle of component combination and strength distribution theory, the energy dissipation density was introduced as the damage variable, and a dynamic mechanical damage constitutive model of sandstone under high temperature was established. The parameters of the constitutive model were fitted under different conditions. It was proved that the fitting curves were in good agreement with the measured curve, which could well describe the dynamic stress-strain relationship of sandstones under realtime high temperature

\section{Data Availability}

The data used to support the findings of this study are included within the article.

\section{Conflicts of Interest}

The authors declare that they have no conflict of interest.

\section{Acknowledgments}

This study was funded by the National Natural Science Foundation of China (grant number 52074240) and the Postgraduate Research and Practice Innovation Program of Province (SJCX21_0978).

\section{References}

[1] C. Kuenzer, J. Zhang, and S. Dech, "Spaceborne thermal infrared observation - an overview of most frequently used sensors for applied research," Thermal Infrared Remote Sensing, vol. 17, 2013.

[2] L. Li, C. A. Tang, S. Y. Wang, and J. Yu, "A coupled thermohydrologic-mechanical damage model and associated application in a stability analysis on a rock pillar," Tunnelling and Underground Space Technology, vol. 34, pp. 38-53, 2013.

[3] A. Mazaira and P. Konicek, "Intense rockburst impacts in deep underground construction and their prevention," Canadian Geotechnical Journal, vol. 52, no. 10, pp. 1426-1439, 2015.

[4] B. Kong, E. Wang, and Z. Li, "The effect of high temperature environment on rock properties-an example of electromagnetic radiation characterization," Environmental Science and Pollution Research, vol. 25, no. 29, pp. 29104-29114, 2018.

[5] S. Liu, J. Xu, and X. Fang, "Assessment of impact mechanical behaviors of rock-like materials heated at $1,000^{\circ} \mathrm{C}$," High Temperature Materials and Processes, vol. 39, no. 1, pp. 489-500, 2020.

[6] Q. Ping, C. Zhang, H. Su, and H. Zhang, "Experimental study on dynamic mechanical properties and energy evolution characteristics of limestone specimens subjected to high temperature," Advances in Civil Engineering, vol. 2020, Article ID 8875568,12 pages, 2020.
[7] Z. Wang and S. Hao, "Study on dynamic compressive mechanical properties and failure modes of heat-treated granite," Latin American Journal of Solids and Structures, vol. 14, no. 4, pp. 657-673, 2017.

[8] S. Liu and J. Xu, "An experimental study on the physicomechanical properties of two post-high- temperature rocks," Engineering Geology, vol. 185, pp. 63-70, 2015.

[9] S. Q. Yang, P. Xu, Y. B. Li, and Y. H. Huang, "Experimental investigation on triaxial mechanical and permeability behavior of sandstone after exposure to different high temperature treatments," Geothermics, vol. 69, no. April, pp. 93-109, 2017.

[10] S. F. Wang, Y. Tang, and S. Y. Wang, "Influence of brittleness and confining stress on rock cuttability based on rock indentation tests," Journal of Central South University, vol. 28, no. 9, pp. 2786-2800, 2021.

[11] X. Liu, W. Lu, M. Li, N. Zeng, and T. Li, “The thermal effect on the physical properties and corresponding permeability evolution of the heat-treated sandstones," Geofluids, vol. 2020, Article ID 8838325, 16 pages, 2020.

[12] P. Hou, X. Liang, F. Gao, J. Dong, J. He, and Y. Xue, "Quantitative visualization and characteristics of gas flow in $3 \mathrm{D}$ porefracture system of tight rock based on Lattice Boltzmann simulation," Journal of Natural Gas Science and Engineering, vol. 89, 2021.

[13] P. Hou, X. Liang, Y. Zhang, J. He, F. Gao, and J. Liu, "3D multiscale reconstruction of fractured shale and influence of fracture morphology on shale gas flow," Natural Resources Research, vol. 30, no. 3, pp. 2463-2481, 2021.

[14] S. Miao, P. Z. Pan, X. Zhao, C. Shao, and P. Yu, "Experimental study on damage and fracture characteristics of Beishan granite subjected to high-temperature treatment with DIC and AE techniques," Rock Mechanics and Rock Engineering, vol. 54, no. 2, pp. 721-743, 2021.

[15] Y. Xue, J. Liu, P. G. Ranjith, X. Liang, and S. Wang, "Investigation of the influence of gas fracturing on fracturing characteristics of coal mass and gas extraction efficiency based on a multi-physical field model," Journal of Petroleum Science and Engineering, vol. 206, 2021.

[16] L. F. Fan, Z. J. Wu, Z. Wan, and J. W. Gao, "Experimental investigation of thermal effects on dynamic behavior of granite," Applied Thermal Engineering, vol. 125, pp. 94-103, 2017.

[17] S. Vidana Pathiranagei, I. Gratchev, and R. Kong, "Engineering properties of four different rocks after heat treatment," Geomechanics and Geophysics for Geo-Energy and GeoResources, vol. 7, no. 1, pp. 1-21, 2021.

[18] G. Lin, M. Li, Y. Chen et al., "Dynamic tensile mechanical properties and fracture characteristics of water-saturated sandstone under the freezing effect," International Journal of Geomechanics, vol. 21, no. 5, 2021.

[19] S. F. Wang, Y. Tang, X. B. Li, and K. Du, "Analyses and predictions of rock cuttabilities under different confining stresses and rock properties based on rock indentation tests by conical pick," Transactions of Nonferrous Metals Society of China, vol. 31, no. 6, pp. 1766-1783, 2021.

[20] M. Li, X. Mao, L. Cao, H. Pu, R. Mao, and A. Lu, "Effects of thermal treatment on the dynamic mechanical properties of coal measures sandstone," Rock Mechanics and Rock Engineering, vol. 49, no. 9, pp. 3525-3539, 2016.

[21] L. Chen, Q. Fang, X. Jiang, Z. Ruan, and J. Hong, “Combined effects of high temperature and high strain rate on normal weight concrete," International Journal of Impact Engineering, vol. 86, pp. 40-56, 2015. 
[22] S. Liu and J. Xu, "Effect of strain rate on the dynamic compressive mechanical behaviors of rock material subjected to high temperatures," Mechanics of Materials, vol. 82, pp. 28-38, 2015.

[23] R. Huang, S. Li, L. Meng, D. Jiang, and P. Li, "Coupled effect of temperature and strain rate on mechanical properties of steel fiber-reinforced concrete," International Journal of Concrete Structures and Materials, vol. 14, no. 1, 2020.

[24] H. Xie, L. Li, R. Peng, and Y. Ju, "Energy analysis and criteria for structural failure of rocks," Journal of Rock Mechanics and Geotechnical Engineering, vol. 1, no. 1, pp. 11-20, 2009.

[25] M. M. He, F. Pang, H. T. Wang, J. W. Zhu, and Y. S. Chen, "Energy dissipation-based method for strength determination of rock under uniaxial compression," Shock and Vibration, vol. 2020, Article ID 8865958, 13 pages, 2020.

[26] R. R. Zhang, L. W. Jing, and Q. Y. Ma, "Experimental study on thermal damage and energy evolution of sandstone after high temperature treatment," Shock and Vibration, vol. 2018, Article ID 3845353, 9 pages, 2018.

[27] T. Yin, K. Peng, L. Wang, P. Wang, X. Yin, and Y. Zhang, "Study on impact damage and energy dissipation of coal rock exposed to high temperatures," Shock and Vibration, vol. 2016, Article ID 5121932, 10 pages, 2016.

[28] M. Li, X. Mao, L. Cao, H. Pu, and A. Lu, "Influence of heating rate on the dynamic mechanical performance of coal measure rocks," International Journal of Geomechanics, vol. 17, no. 8, 2017.

[29] Z. L. Wang, S. Y. Hao, J. Zheng, N. C. Tian, F. S. Zha, and H. Shi, "Study on energy properties and failure behaviors of heat-treated granite under static and dynamic compression," Mechanics of Advanced Materials and Structures, vol. 27, no. 6, pp. 462-472, 2020.

[30] R. H. Shu, T. B. Yin, X. B. Li, Z. Q. Yin, and L. Z. Tang, "Effect of thermal treatment on energy dissipation of granite under cyclic impact loading," Transactions of Nonferrous Metals Society of China, vol. 29, no. 2, pp. 385-396, 2019.

[31] D. Ma, Q. Ma, and P. Yuan, "SHPB tests and dynamic constitutive model of artificial frozen sandy clay under confining pressure and temperature state," Cold Regions Science and Technology, vol. 136, pp. 37-43, 2017.

[32] Z. L. Wang, H. Shi, and J. G. Wang, "Mechanical behavior and damage constitutive model of granite under coupling of temperature and dynamic loading," Rock Mechanics and Rock Engineering, vol. 51, no. 10, pp. 3045-3059, 2018.

[33] C. Wang, S. F. Zhan, M. Z. Xie, C. Wang, L. P. Cheng, and Z. Q. Xiong, "Damage characteristics and constitutive model of deep rock under frequent impact disturbances in the process of unloading high static stress," Complexity, vol. 2020, Article ID 2706091, 15 pages, 2020.

[34] X. S. Liu, Y. L. Tan, J. G. Ning, Y. W. Lu, and Q. H. Gu, "Mechanical properties and damage constitutive model of coal in coal-rock combined body," International Journal of Rock Mechanics and Mining Sciences, vol. 110, pp. 140-150, 2018.

[35] B. Du and H. Bai, "A damage constitutive model of red sandstone under coupling of wet-dry cycles and impact load," Shock and Vibration, vol. 2019, 12 pages, 2019.

[36] C. Fairhurst and J. A. Hudson, "Discussion," International Journal of Rock Mechanics and Mining Sciences, vol. 36, no. 3, pp. 279-289, 1999.

[37] A. Carpinteri, G. Lacidogna, and N. Pugno, "Scaling of energy dissipation in crushing and fragmentation: a fractal and statistical analysis based on particle size distribution," International Journal of Fracture, vol. 129, no. 2, pp. 131-139, 2004.
[38] L. Turcotte, "Fractals and fragmentation," Journal of Geophysical Research, vol. 91, no. B2, pp. 1921-1926, 1986.

[39] C. D. Su, W. B. Guo, and X. S. Li, "Experimental research on mechanical properties of coarse sandstone after high temperatures," Chinese Journal of Rock Mechanics and Engineering, vol. 27, 2008.

[40] X. B. Li, T. S. Lok, J. Zhao, and P. J. Zhao, "Oscillation elimination in the Hopkinson bar apparatus and resultant complete dynamic stress-strain curves for rocks," International Journal of Rock Mechanics and Mining Sciences, vol. 37, no. 7, pp. 1055-1060, 2000.

[41] Z. X. Zhang, S. Q. Kou, L. G. Jiang, and P.-A. Lindqvist, "Effects of loading rate on rock fracture," International Journal of Rock Mechanics and Mining Sciences, vol. 36, no. 5, pp. 597611, 1999.

[42] L. Weng, Z. Wu, Q. Liu, and Z. Wang, "Energy dissipation and dynamic fragmentation of dry and water-saturated siltstones under sub-zero temperatures," Engineering Fracture Mechanics, vol. 220, p. 106659, 2019.

[43] T. Yin, L. Bai, X. Li, X. Li, and S. Zhang, "Effect of thermal treatment on the mode I fracture toughness of granite under dynamic and static coupling load," Engineering Fracture Mechanics, vol. 199, pp. 143-158, 2018.

[44] J. Xu and S. Liu, "Analysis of energy dissipation rule during deformation and fracture process of rock under high temperatures in shpb test," Chinese Journal of Rock Mechanics and Engineering, vol. 32, no. S2, pp. 3109-3115, 2013.

[45] T. F. Chen, J. Y. Xu, S. Liu, P. Wang, and X. Fang, "Experimental study on dynamic mechanical properties of sandstone after experiencing different high temperatures," Explosion and Shock Waves, vol. 34, 2014.

[46] L. Zhang, X. Mao, R. Liu, X. Guo, and D. Ma, “The mechanical properties of mudstone at high temperatures: an experimental study," Rock Mechanics and Rock Engineering, vol. 47, no. 4, pp. 1479-1484, 2014.

[47] P. Wang, J. Y. Xu, S. Liu, and T. F. Chen, "Research on dynamic mechanical properties of sandstone at high temperature," Acta Armamentarii, vol. 34, no. 2, pp. 203-208, 2013.

[48] J. Xu and S. Liu, "Research on fractal characteristics of marble fragments subjected to impact loading," Rock and Soil Mechanics, vol. 33, no. 11, pp. 3225-3229, 2012.

[49] L. Wang, H. Su, S. Chen, and Y. Qin, "Nonlinear dynamic constitutive model of frozen sandstone based on Weibull distribution," Advances in Civil Engineering, vol. 2020, Article ID 6439207, 10 pages, 2020.

[50] G. Zhao, L. Xie, and X. Meng, "A damage-based constitutive model for rock under impacting load," International Journal of Mining Science and Technology, vol. 24, no. 4, pp. 505-511, 2014.

[51] Y. Liu and F. Dai, "A damage constitutive model for intermittent jointed rocks under cyclic uniaxial compression," International Journal of Rock Mechanics and Mining Sciences, vol. 103, no. November, p. 289, 2018.

[52] Z. L. Wang, Y. C. Li, and J. G. Wang, "A damage-softening statistical constitutive model considering rock residual strength," Computational Geosciences, vol. 33, no. 1, pp. 1-9, 2007.

[53] T. Yin, P. Wang, J. Yang, and X. Li, "Mechanical behaviors and damage constitutive model of thermally treated sandstone under impact loading," IEEE Access, vol. 6, pp. 72047-72062, 2018.

[54] J. Lemaitre, "How to use damage mechanics," Nuclear Engineering and Design, vol. 80, no. 2, pp. 233-245, 1984. 